Review

\title{
Atypical roles of the Chemokine Receptor ACKR3/CXCR7 in Platelet Pathophysiology Madhumita Chatterjee ${ }^{1 *}$
}

Dept. of Cardiology and Angiology, University hospital Tübingen; madhumita.chatterjee@med.unituebingen.de

* Correspondence: madhumita.chatterjee@med.uni-tuebingen.de; Tel.:+497071-29-82888

\begin{abstract}
The manifold actions of the pro-inflammatory and regenerative chemokine CXCL12/SDF$1 \alpha$ are executed through the canonical GProteinCoupledReceptor CXCR4, and the non-canonical ACKR3/CXCR7. Platelets express CXCR4, ACKR3/CXCR7, and are a vital source of CXCL12/SDF$1 \alpha$ themselves. In recent years, a regulatory impact of the CXCL12-CXCR4-CXCR7 axis on platelet biogenesis i.e. megakaryopoiesis, thrombotic and thrombo-inflammatory actions have been revealed through experimental and clinical studies. Platelet surface expression of ACKR3/CXCR7 is significantly enhanced following myocardial infarction (MI) in acute coronary syndrome (ACS) patients, also associated with improved functional recovery and prognosis. The therapeutic implications of ACKR3/CXCR7 in myocardial regeneration and improved recovery following an ischemic episode, are well documented. Cardiomyocytes, cardiac-fibroblasts, endothelial lining of the blood vessels perfusing the heart, besides infiltrating platelets and monocytes, all express ACKR3/CXCR7. This review recapitulates ligand induced differential trafficking of platelet CXCR4-ACKR3/CXCR7 affecting their surface availability, and in regulating thrombo-inflammatory platelet functions and survival through CXCR4 or ACKR3/CXCR7. It emphasizes the pro-thrombotic influence of CXCL12/SDF-1 $\alpha$ exerted through CXCR4, as opposed to the anti-thrombotic impact of ACKR3/CXCR7. Offering an innovative translational perspective, this review also discusses the advantages and challenges of utilizing ACKR3/CXCR7 as a potential anti-thrombotic strategy in platelet associated cardiovascular disorders, particularly in coronary artery disease (CAD) patients postMI.
\end{abstract}

Keywords: Platelet, ACKR3/CXCR7, Thrombosis, Thrombo-inflammation, Anti-platelet therapy, Cardiovascular disease, Coronary artery disease

\section{Introduction}

Platelets are versatile cells in circulation that relentlessly patrol the blood vessels as sentinels detecting vascular injury, mount hemostasis, sense pathogenic intrusion and execute thrombo-inflammatory response in coordination with the immune system [1-4]. The role of platelets in instigating thrombotic occlusion of the coronary artery causing thrombo-ischemic events like MI, infiltration of activated platelets into the affected myocardium leading to either deleterious or regenerative consequences are widely investigated [5-7]. The balance between these opposing actions and the resultant outcome depends on the contribution of activated platelets and platelet-derived factors while escalating an acute inflammatory response following MI in compliance with monocytes and neutrophils; and subsequently in prompting resolution of the inflammatory process leading to myocardial regeneration and functional recovery [7]. Platelets are a readily available cargo of functionally opposing inflammatory (CXCL4, CCL5) and anti-inflammatory (IL-10) cytokines/chemokines, angiogenic (VEGF) as opposed to anti-angiogenic (endostatin) mediators, growth factors (PDGF, TGF- $\beta$ ) [8], which can be delivered and enriched locally at the site of myocardial damage. Thereby platelets may direct the course of cardiac regeneration or fibrosis $[7,9,10]$. Platelets are an enriched source of TGF- $\beta$, which is a major pro-fibrotic factor that triggers collagen synthesis and mediates tissue remodeling [11]. At the same time activated platelet derived CXCL12/SDF1 $\alpha$ has distinctive regenerative potential in facilitating the migration of endothelial progenitor cells [12-14], and in promoting the differentiation of monocytes into reparative M2-macrophages instead of a pro-inflammatory M1-phenotype $[15,16]$. Platelet surface expression of CXCL12/SDF1 $\alpha$ is significantly 
enhanced in ACS patients, particularly in those with reduced $(<55 \%)$ left ventricular ejection fraction (LVEF) [17]. Platelet surface-associated CXCL12/SDF1 $\alpha$ correlates positively with the extent of platelet activation (e.g. CD62P) signifying granular release; it also correlates with the number of circulating $\mathrm{CD}_{3} 4^{+}$progenitor cells and $\mathrm{CD} 34^{+} \mathrm{CD} 133^{+}$endothelial progenitor cells (EPCs) [17]. Platelets adherent on endothelial cells express substantial amounts of CXCL12/SDF1 $\alpha$, which effectively recruits $\mathrm{CD}_{34}{ }^{+}$progenitor cells; while activated platelet derived CXCL12/SDF1 $\alpha$ promotes subsequent differentiation of $\mathrm{CD}^{+} 4^{+}$progenitor cells into EPCs [13]. Percentage of circulatory plateletprogenitor cell aggregates are significantly enhanced in ACS, particularly in patients with ST-elevation myocardial infarction (STEMI), who also exhibit a CXCL12/SDF1 $\alpha$ enriched platelet surface. Following acute myocardial infarction (AMI), patients with increased platelet-CD34+-aggregates assessed at baseline, show less deteriorated infarct size and better LVEF-recovery during a 3-month follow-up. Since aggregate formation with platelets facilitates the adhesion of $\mathrm{CD} 34^{+}$progenitors onto extracellular matrix and endothelial cells, platelet-progenitor cell aggregates are suggested in supporting domiciliation of $\mathrm{CD} 34^{+}$progenitor cells to the affected microvasculature after AMI $[18,19]$. Platelet surface-associated or activated platelet derived CXCL12/SDF1 $\alpha$ acts as a prominent mediator in influencing these regenerative processes $[19,20]$.

CXCL12/SDF1 $\alpha$ either from autocrine or paracrine cellular sources also exerts a significant influence on platelet functions and survival by engaging its receptors CXCR4 and ACKR3/CXCR7 $[8,15,21]$. Over the years we have explored the pathophysiological relevance of platelet CXCL12CXCR4-CXCR7 axis in the context of CAD. Like CXCL12/SDF1 $\alpha$, [22] platelets from CAD patients exhibit enhanced surface expression of CXCR4, and ACKR3/CXCR7 [23] as compared to healthy subjects. ACKR3/CXCR7 surface expression is particularly increased in ACS as compared to stableCAD patients. It also correlates with platelet surface-associated CXCL12/SDF1 $\alpha$ [23]. Moreover, platelet ACKR3/CXCR7 surface expression ascertained upon admission immediately following an acute thrombo-ischemic event, is associated with significantly improved functional recovery (LVEF) and prognosis [23], [24], evaluated during a hospital stay of 5 days, and over a 6 months follow-up period. The prognostic significance of platelet CXCR4 surface expression at baseline, which though comparable between stable CAD and ACS patients, becomes more prominent after a 1-year follow up. Symptomatic CAD patients exhibiting lower levels of platelet CXCR4 surface expression at baseline succumb to all-cause death and/or MI to a significant extent. Within the same time-frame although lower surface expression of ACKR3/CXCR7 is found to be associated with all-cause of mortality in symptomatic CAD patients, its prognostic association with death on account of recurrent MI appears to be less pronounced [25]. Evidence on platelet CXCR4 and ACKR3/CXCR7 surface expression from a longitudinal cohort is currently lacking and could be investigated to ascertain their impact on long term prognosis. At present one can only speculate a few possibilities. Expression of ACKR3/CXCR7 is significantly increased at the infarct border zone of myocardium [26-28], and peri-infarct regions of the brain [29] following an acute thrombo-ischemic episode, in animal models [27,28,30,31] and humans alike [26,28,32]. Firstly, target organ (e.g. myocardium) specific expression of ACKR3/CXCR7 might either override or be complemented by the impact of platelet ACKR3/CXCR7 in repair and regenerative mechanisms. Since activated platelets infiltrate ischemia affected myocardium $[5,7,33,34]$, they can actively regulate the balance between inflammation vs regeneration [7]. The extent to which platelet ACKR3/CXCR7 may influence this functional outcome, superseding the acclaimed regenerative drive of ACKR3/CXCR7 highly expressed in cardiomyocytes [26] and endothelial cells [27], is uncertain. Cardiomyocytes, like circulating platelets [22] exhibit increased expression of CXCL12/SDF1 $\alpha$ following MI, which significantly influences the migration of CXCR4 and ACKR3/CXCR7 expressing cardiac stem cells with regenerative potential [35]. Secondly, it has been shown in CAD patients that ACKR3/CXCR7 mediated signaling involving Erk regulates the re-endothelialization capacity of regenerative endothelial outgrowth cells (EOC), which play an important role in revascularization of the ischemic organ, quite independent of any influence from circulating platelets. However, EOC from CAD patients show reduced expression of ACKR3/CXCR7 as compared to healthy subjects [36]. The differential impact of platelet CXCR4 and ACKR3/CXCR7 on long-term (1-year) prognosis for recurrent MI [25] could be due to difference in their expression pattern on platelets. CXCR4 surface expression is relatively more prominent under physiological conditions [37], while ACKR3/CXCR7 may be transiently induced post-MI [23] by circulatory or platelet-associated CXCL12/SDF1 $\alpha$ in ACS patients [22,38], through receptor trafficking as discussed next. 


\subsection{The typical and the atypical: differential trafficking of CXCR4-CXCR7 in platelets}

The relative surface abundance of Gai-coupled canonical CXCR4 and non-canonical ACKR3/CXCR7 on platelets and immune cells (e.g. monocytes [16] and lymphocytes [39]) can directly influence their extent of functional engagement in different pathophysiological processes. CXCR4 and ACKR3/CXCR7 are constitutively expressed at transcript and protein levels in human platelets, but CXCR4 surface expression predominates over ACKR3/CXCR7 [37,40]. We have demonstrated that CXCR4 and ACKR3/CXCR7 are shared by pro-inflammatory physiological ligands- CXCL12/SDF-1 $\alpha$ and microphage migration inhibitory factor (MIF), while CXCL11 is an exclusive ligand for ACKR3/CXCR7 [37,40]. Presence of CXCL12/SDF-1 $\alpha$, CXCL11 and MIF in the immediate microenvironment of platelets may induce a dynamic alteration in CXCR4 and ACKR3/CXCR7 surface expression as CXCR4 is internalized and ACKR3/CXCR7 is preferentially translocated to the platelet surface in response to CXCL12/SDF-1 $\alpha$ [37] but not CXCL11 or MIF [40].

CXCL12/SDF-1 $\alpha$-induced CXCR4 internalization precedes and is a pre-requisite for ACKR3/CXCR7 surface externalization, which is counteracted by a blocking antibody directed against CXCR4 or by CXCR4-antagonist AMD3100. This bidirectional shuttling of CXCR4 and ACKR3/CXCR7 is executed through Erk, which interacts with and phosphorylates the intracellular molecular chaperone Cyclophilin A (CyPA). Both CXCR4 and ACKR3/CXCR7 biophysically interact with CyPA in platelets. The peptidyl prolyl transferase (PPIase) activity of CyPA is essential for ACKR3/CXCR7 translocation to the platelet surface, therefore, counteracted by a CyPA inhibitor NIM-811, and ablated in platelets from Cypa-/- mice. Ubiquitination of ACKR3/CXCR7 determines its shuttling between cytosol and the cell membrane [41]. CXCL12/SDF-1 $\alpha$ induces ubiquitination of ACKR3/CXCR7 involving E1-ligase activity, and translocates ACKR3/CXCR7 to the platelet surface [37]. MIF induces CXCR4 internalization like CXCL12/SDF-1 $\alpha$, but cannot transduce intracellular signals (i.e. downstream Erk phosphorylation) required for ACKR3/CXCR7 externalization. This is because platelets lack CD74, which essentially acts as a co-receptor for MIF along with CXCR4 [40,42]. ACKR3/CXCR7 specific ligand CXCL11 does not affect CXCL12/SDF1 $\alpha$-induced CXCR4 internalization, but internalizes ACKR3/CXCR7 and may counteract CXCL12/SDF1 $\alpha$-induced ACKR3/CXCR7 externalization, if present simultaneously in the microenvironment [40]. Such an interplay of physiological ligands at the site of vascular inflammation either from another paracrine source or activated platelets themselves, may directly regulate surface availability of CXCR4 and ACKR3/CXCR7, and their functional engagement. Circulatory levels of CXCL12/SDF1 $\alpha$ $[38,43]$ and MIF [44] are elevated in ACS patients, furthermore, associated with progressive disease severity. Therefore, CXCL12/SDF1 $\alpha$ and MIF in circulation may influence the relative surface expression and involvement of CXCR4-ACKR3/CXCR7 in modulating platelet response and survival potential [24]. Although both CXCR4 and ACKR3/CXCR7 serve as cognate receptors for CXCL12/SDF-1 $\alpha$ and MIF, they are involved in quite contrasting functional responses as discussed next [21].

\subsection{The pro-thrombotic attributes of canonical CXCR4}

CXCL12/SDF-1 $\alpha$ acting through CXCR4 can substantiate cell migration, proliferation, differentiation, and survival $[15,16,45-48]$. The CXCL12/SDF- $1 \alpha$ gradient modulated by CXCR4 in the bone marrow vascular niche influences maturation of megakaryocytes, the formation of proplatelet extension and release of platelets into the perfusing vessels, during platelet biogenesis i.e. megakaryopoiesis (Figure 1) [49-54]. Much like their parental cells, mature platelets can transmigrate through the endothelium following a CXCL12/SDF-1 $\alpha$ gradient sensed through CXCR4, which is inhibited by CXCR4 antagonist AMD3100, G $\alpha$ i inhibitor pertussis toxin, PI3K inhibitors LY294002 or wortmannin, and by disrupting actin polymerization with cytochalasin B $[55,56]$. Therefore CXCL12/SDF-1 $\alpha$ may actively sequester platelets by engaging platelet CXCR4 at the site of vascular lesion, atheroprogression or at CXCL12/SDF-1 $\alpha$-enriched atherosclerotic plaques [57].

Experimental studies have shown that recombinant CXCL12/SDF-1 $\alpha$, mimicking that from a paracrine source, or activated platelets induces intracellular calcium mobilization, augments aggregation [57-61] and thrombotic potential exclusively through Gai coupled CXCR4 (Figure 1) and not ACKR3/CXCR7 engagement. This response is counteracted by a CXCR4 blocking antibody, CXCR4antagonist AMD3100 and pertussis toxin [57-59,61]. Interestingly, decreased platelet surface expression of CXCR4 results in impaired CXCL12/SDF1 $\alpha$ triggered aggregatory response in patients 
with inherited thrombocytopenia [62]. CXCL12/SDF-1 $\alpha$ can enhance platelet adhesion to extracellular matrix components like collagen and fibrinogen under static or arterial flow conditions [58], and increase platelet spreading in the presence of plasma lipoproteins (low density lipoproteinLDL, oxisized low density lipoprotein-oxLDL) [63]. Besides, CXCL12/SDF-1 $\alpha$ induced morphological changes leading to blebing in platelets may also enhance blood coagulation [58]. In suspension, CXCL12/SDF-1 $\alpha$ synergizes with collagen and convulxin triggered release of thrombo-inflammatory mediators like platelet derived growth factor (PDGF), sCD40L by driving p38MAPK activation, and instigates release of phosphorylated- heat shock protein 27 (HSP27) from activated platelets. CXCL12/SDF-1 $\alpha$ is considered to be a weak platelet agonist and requires synergistic stimuli from the microenvironment in form of collagen, plasma components like serotonin (5-hydroxy tryptophan-5HT), thromboxane ( $\mathrm{Tx}_{2}$ ), adenosine -di-phosphate (ADP), lipoproteins (LDL, oxLDL), or shear stress [58]. Therefore, as a pro-thrombotic mediator CXCL12/SDF-1 $\alpha$ is effective in platelet rich plasma (PRP) preparations, not washed platelets, and under stirring but not non-stirring conditions [58,61]. CXCL12/SDF-1 $\alpha$ can exert a synergistic effect with platelet activating stimuli to prompt phospholipase $C$ activation, intracellular calcium mobilization, P-selectin exposure, $\alpha_{\text {Irb }} \beta_{3}-$ integrin activation, granular release from $\alpha$ - (e.g. CXCL4) and dense granules (e.g. ADP, ATP), generation of $\mathrm{TxA}_{2}$, all of which substantiate pro-thrombotic response. At lower concentrations CXCL12/SDF-1 $\alpha$ may induce the primary phase of aggregation but instigates a full biphasic aggregation response with increasing concentrations [60]. CXCL12/SDF-1 $\alpha$ synergistically enhances aggregation induced by subthreshold concentrations of strong agonists like thrombin and ADP, or relatively weaker agonists like 5HT, under arterial and lower shear stress conditions [58,60]. These effects are sensitive to CXCR4 and $\mathrm{P}_{2} \mathrm{Y}_{12}$ antagonism, apyrase, pharmacological inhibition of prostanoid production through COX-1 (aspirin), PI3K (wortmannin and LY29004), and tyrosine kinases (genistin) [57]. CXCR4 ligation by CXCL12/SDF1 $\alpha$ triggers the platelet activatory signaling cascade involving PI3K, Akt, PDK1, GSK3 $\beta$ causing myosin light chain phosphorylation [64]. Ex vivo supplementation with recombinant CXCL12/SDF1 $\alpha$, or its in vivo administration enhances thrombus formation [59,63] over collagen coated surface and in the injured artery [63] (Figure 1). CXCL12/SDF-1 $\alpha$ also elicits a synergistic influence on the activating stimuli from plasma lipoproteins (LDL, oxLDL) to augment degranulation (CD62P surface expression), $\alpha_{\mathrm{IIb}} \beta 3$-integrin activation (PAC-1 binding), spreading, and thrombus formation [63]. This is of particular significance, as both platelet surface-associated CXCL12/SDF1 $\alpha[12,17]$ and oxLDL [65], also intraplatelet levels of oxLDL are enhanced in ACS patients [63], and could account for platelet hyper-reactivity.

Acting through the Gai-coupled canonical CXCR4, CXCL12/SDF-1 $\alpha$ downregulates the production of platelet inhibitory cAMP and even antagonizes PGI2 analog induced cAMP levels [59]. Such actions may lower the activation threshold of circulating platelets under conditions where levels of circulatory CXCL12/SDF-1 $\alpha$ are enhanced (e.g. in CAD patients) [38]. Moreover, activated platelet-derived CXCL12/SDF-1 $\alpha$ acting in an autocrine manner, exclusively through CXCR4 and not ACKR3/CXCR7, promotes platelet aggregation, ATP release, intracellular calcium mobilization, thromboxane production and thrombus formation [59] (Figure 1). Such actions may foster thrombotic response in a pro-inflammatory microenvironment where platelets accumulate. Therefore, antagonizing the CXCL12/SDF-1 $\alpha$-CXCR4 axis may offer therapeutic benefits [66-68] in regulating the pro-thrombotic drive of platelets.

\subsection{ACKR3/CXCR7 boosts platelet survival}

ACKR3/CXCR7 is a prominent prosurvival receptor for primary and tumor cells alike. Aged and activated platelets are removed from circulation and eliminated in the reticulo-endothelial system and spleen [69], while precursor megakaryocytes release newly formed platelets into the bone marrow vasculature to maintain a steady turnover of functionally adept platelets in circulation. Since both aged and apoptotic platelets have reduced functional capacities [70], platelet response can not only be influenced by their activation status but survival potential as well [71]. CXCL11, CXCL12 and MIF as physiological ligands of ACKR3/CXCR7 counteract apoptosis induced upon platelet activation by stimulatory agonists (e.g. thrombin), and that induced by pharmacological BH3-mimetic (ABT-737). Moreover, CXCL12/SDF-1 $\alpha$ and MIF prolong the survival of circulating platelets through ACKR3/CXCR7 engagement [37,40] (Figure 1). Pharmacological inhibition of the Erk1/2 pathway (U0126), or CyPA-PPIase activity (NIM811) uncouples CXCR4-ACKR3/CXCR7 
trafficking from the resultant anti-apoptotic effects of recombinant CXCL12/SDF- $1 \alpha$ mediated through ACKR3/CXCR7. The anti-apoptotic effects of recombinant CXCL11 and MIF upon ACKR3/CXCR7 ligation are executed through downstream activation of the PI3K-Akt-pathway which culminates in Akt mediated phosphorylation and thereby inactivation of the pro-apoptotic effector protein BAD. Therefore, this anti-apoptotic impact is abolished in murine platelets lacking Akt. These experimental evidences suggested the possibility that elevated plasma levels of CXCL12/SDF-1 $\alpha$ [38] and MIF [44] in ACS patients might exert a similar influence on circulatory platelet survival. Subsequent clinical evidence from STEMI patients have indeed shown a significantly positive correlation between enhanced CXCR4, ACKR3/CXCR7 surface expression and survival potential of platelets. However, the relative functional efficacy of these aged platelets [70] in circulation as compared to newly released platelets through ongoing megakaryopoiesis [72], also their regenerative involvement in tissue repair or functional recovery [73] remains to be ascertained.

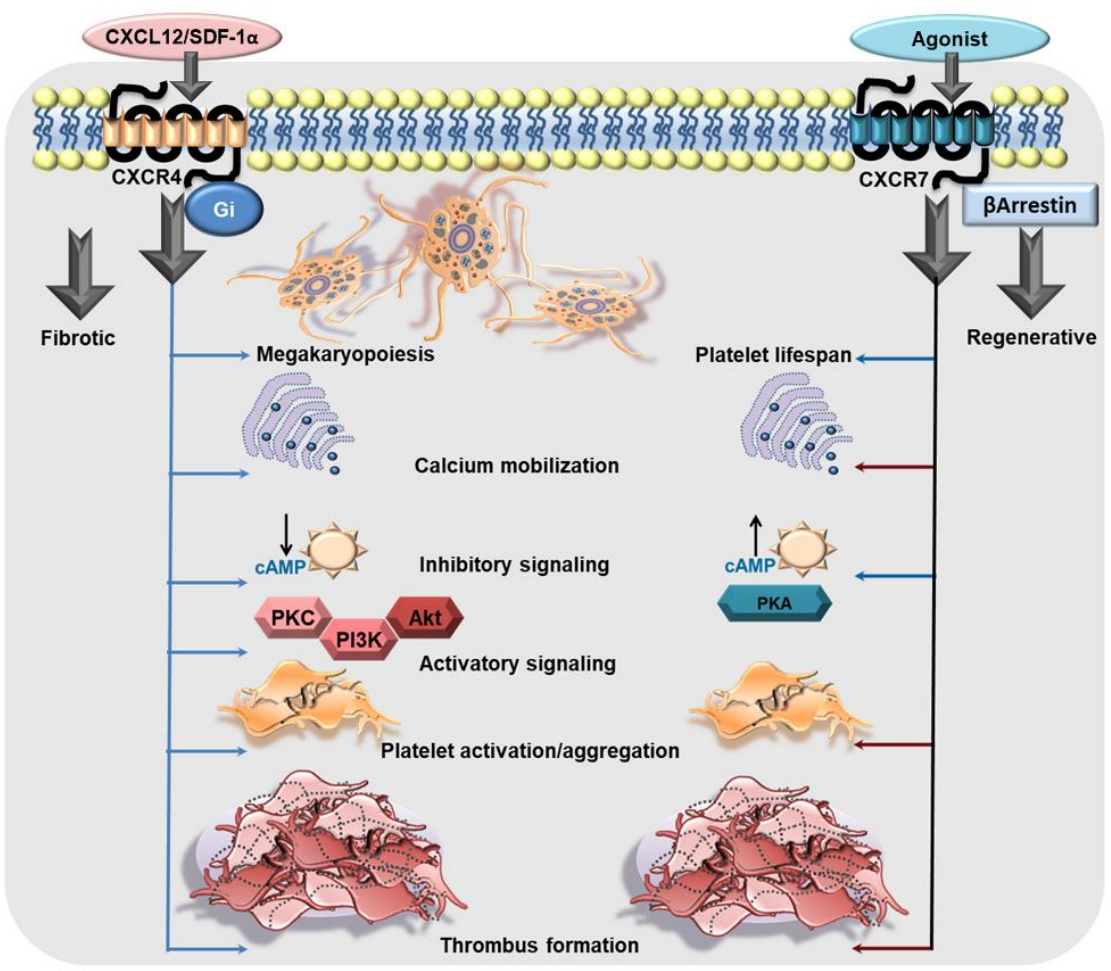

Figure 1. The functional dichotomy of CXCR4 and ACKR3/CXCR7 in platelets. CXCR4 is a Gaicoupled GPCR which may exert its influence on platelet biogenesis (megakaryopoiesis), and prothrombotic response. CXCL12/SDF1 $\alpha$ engages CXCR4 on platelets to trigger intraplatelet-calcium mobilization, the platelet activatory signaling pathway involving PI3K, Akt, which promotes platelet activation, aggregation, and a pro-thrombotic response. Moreover, G $\alpha \mathrm{i}$-coupled CXCR4 induces a canonical signaling cascade following ligation by CXCL12/SDF- $1 \alpha$ that imposes an inhibitory effect on AC and impedes generation of CAMP. On the contrary, ACKR3/CXCR7 is an atypical GPCR which does not engage a $G$ protein but mostly $\beta$-arrestin. Physiological and pharmacological ligands of ACKR3/CXCR7 promote platelet survival. ACKR3/CXCR7-ligation by a pharmacological agonist (VUF11207) counteracts calcium mobilization induced by platelet activating stimuli. ACKR3/CXCR7-ligation triggers the platelet inhibitory signaling cascades involving AC-CAMPPKA, while counteracting activatory signaling mediators to impose an inhibition on platelet activation, degranulation, aggregation and pro-thrombotic response (red arrows denote an inhibitory effect on the process). This exemplifies the functional dichotomy of platelet CXCR4 and ACKR3/CXCR7 in mediating pro and anti-thrombotic effects respectively.

\subsection{Atypical influence of ACKR3/CXCR7 on thrombotic and thrombo-inflammatory platelet response}

2.4.1 Physiological CXCR7-agonist MIF: Recombinant MIF does not exert any effect on the activation status of platelets either alone or synergistically in combination with activating stimuli, as ascertained by P-selectin (CD62P) surface exposure or degranulation of the proinflammatory 
chemokine CCL4 from $\alpha$-granules [74,75]. MIF does not regulate spreading of platelets over fibrinogen, also ruling out the possibility of an influence on $\alpha_{\mathrm{IIb}} \beta_{3}$-integrin activation. Therefore, unlike CXCL12/SDF-1 $\alpha$, MIF does not alter platelet aggregation response to ADP, or TxA2 analog. Contrary to CXCL12/SDF-1 $\alpha$, MIF does not trigger intraplatelet calcium mobilization in TxA2 receptor agonist (U46619) treated platelets; however, both CXCL12/SDF-1 $\alpha$ and MIF can desensitize platelets to increases in calcium transients triggered by ADP [74]. As a consequence of the prosurvival effect mediated through ACKR3/CXCR7, MIF attenuates exposure of pro-thrombotic phosphatidylserine on the surface of pro-coagulant platelets. Therefore, MIF exercises an anti-thrombotic effect in $e x$ vivo flow chamber assay and retards arterial thrombus build up in vivo. This effect on thrombus stability is counteracted by blocking ACKR3/CXCR7 [40]. Although experimental evidences documented so far relate the functional dichotomy of CXCR4 as a pro-thrombotic and ACKR3/CXCR7 as an anti-thrombotic mediator (Figure 1), the contribution of ACKR3/CXCR7 to platelet pathophysiology warrants further in-depth investigation.

2.4.2 Anti-thrombotic effects of pharmacological agonist VUF11207: Continuing our previous investigation showing enhanced surface availability of ACKR3/CXCR7 on circulating platelets in CAD patients [23,25], and the possibility of regulating thrombotic response through ACKR3/CXCR7, as observed with MIF [40], we are currently corroborating the therapeutic implication of platelet ACKR3/CXCR7 as a potential anti-thrombotic drug target using pharmacological CXCR7-agonist. Our recent finding shows that unlike MIF, pharmacological CXCR7-agonist (VUF11207) can interfere with platelet degranulation from both $\alpha$-(CD62P surface expression, release of thrombo-inflammatory cytokines and chemokines) and $\delta$-(CD63, ATP) granules, modulate $\alpha_{\mathrm{IIb}} \beta_{3}$-integrin activation, platelet interaction with and adhesion to physiological matrices (collagen and fibrinogen), and aggregation response to different stimuli [76]. Like MIF, CXCR7-agonist VUF11027 inhibits thrombus formation over collagen in ex vivo flow chamber assay and is efficacious in both human and murine systems (Figure 2). This offered us the possibility of its pre-clinical validation in murine models of arterial thrombosis, and in regulating thrombotic, thrombo-inflammatory platelet response following myocardial infarction/reperfusion injury (MI/RI)[76]. CXCR7-agonist administration reduces platelet degranulation, $\alpha_{\mathrm{IIb}} \beta_{3}$-integrin activation and thrombotic propensity $24 \mathrm{hrs}$ post-MI; also counteracts thrombus build-up, prolonging time to vessel occlusion following $\mathrm{FeCl}_{3}$-inflicted carotid artery injury. Ex vivo treatment of blood from ACS patients with CXCR7-agonist reduces degranulation, integrin activation, ADP, TRAP, collagen induced platelet aggregation and thrombus formation. This offers us the possibility to exploit enhanced availability of ACKR3/CXCR7 on platelet surface $[23,25]$ as a potential anti-thrombotic drug target post-MI in ACS patients. Similar to the physiological ACKR3/CXCR7 ligand MIF, pharmacological CXCR7-agonist VUF11207 reduces phosphatidylserine exposure and percentage of procoagulant platelets upon activation, without affecting basal levels. Consequently, presence of CXCR7-agonist counteracts activated platelet-driven procoagulant response e.g. thrombin generation, or ADP-induced clot formation in thromboelastographic assays, but it does not interfere with basal hemostatic response or plasma coagulation. Therefore, administration of CXCR7-agonist does not increase bleeding time in mice or affect plasma coagulation profile (activated partial thromboplastin time-APTT, pro-thrombin time-PT)[76]. The possibility of sparing basal hemostatic response but counteracting pathological thrombosis is seemingly an advantageous feature in such a novel anti-thrombotic strategy under consideration.
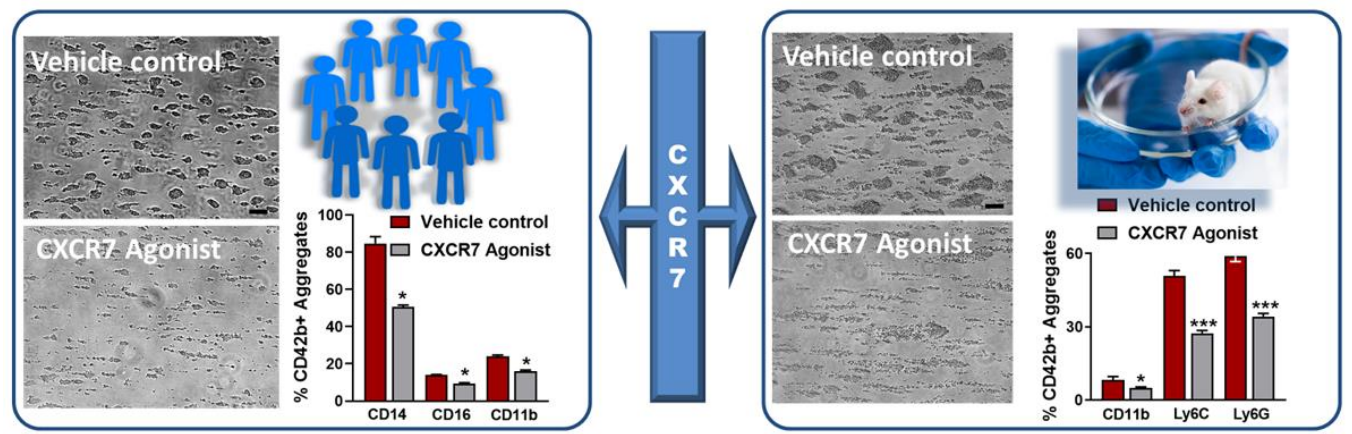

Figure 2. CXCR7-agonist reduces thrombotic response and thrombo-inflammatory platelet interaction with leukocytes ex vivo. Blood from healthy human subjects or mice pre-treated with vehicle control $(1 \% \mathrm{DMSO})$ or CXCR7-agonist $(100 \mu \mathrm{g} / \mathrm{mL})$ for 30 minutes at room temperature is perfused 
through a transparent flow chamber (slit depth $50 \mu \mathrm{m})$ over a collagen $(100 \mu \mathrm{g} / \mathrm{mL})$-coated surface at $1700 \mathrm{~s}^{-1}$ (human) or $1000 \mathrm{~s}^{-1}$ (murine) wall shear rate. After blood perfusion, the chamber is rinsed with PBS and images are captured from randomly chosen microscopic areas (Axiovert 200, Carl Zeiss, optical objective 20x). Phase contrast images for relative thrombus coverage shows decreased thrombus formation in CXCR7-agonist treated human and murine blood. Bar=20 $\mu \mathrm{m}$. Effluent blood from the flow chamber is collected and analyzed for platelet-leukocyte aggregate formation by flow cytometry using platelet (CD42b) and leukocyte population specific surface markers (CD14, CD16, Ly6G, Ly6C). Bar diagram shows platelet-leukocyte aggregate formation is significantly reduced in the presence of CXCR7-agonist as compared to vehicle control. Data are mean \pm S.E.M from 5 independent experiments performed with blood $n=5$ healthy subjects and $n=5$ C57BL/6J mice. * $p<0.05$, *** $\mathrm{p}<0.001$ with Mann-Whitney U-test.

2.4.3 VUF11207 counteracts thrombo-inflammatory platelet functions: Platelets are versatile cells which not only mediate hemostasis but also thrombo-inflammatory adversities that can exaggerate vascular and microvascular thrombosis in the veins [77], arteries [78], and pulmonary micro-capillaries [79]. Thrombo-inflammatory mediators released from activated platelets may influence the severity of organ damage during the acute inflammatory phase post infarct, also participate in subsequent resolution of the inflammatory process, facilitating gradual regeneration, remodeling and functional recovery [80,81]. Moreover, platelet-derived soluble mediators (e.g.IL-1 $\beta, s C D 40 L)$ add to the circulatory levels from other cellular sources during acute inflammation $[82,83]$ or chronic atheroprogression [84]. Therefore thrombo-inflammatory attributes of platelets are being extensively investigated in search of novel therapeutic interventions in cardiovascular disease $[2,81,85]$, and immunothrombotic complications instigated by Fc $\gamma$ RIIA-mediated [86] activation of platelets. Platelet-leukocyte associations [87] play a significant role in aggravating thrombotic complications $[82,85]$. Increased formation of platelet-monocyte aggregates are observed in the circulation of ACS patients [88], attributed to elevated levels of pro-inflammatory sP-selectin, IL-6, which confers increased risk of ACS. Similarly, platelet-neutrophil interactions in heparin induced thrombocytopenia-(HIT)[77] enhance thrombotic disposition. Considering the need for innovative anti-platelet approaches $[81,84,85]$, the inefficacy of aspirin [89] in reducing immunothrombosis-associated mortality, further research is required in this direction.

In our ongoing investigation we observed that CXCR7-agonist inhibits formation of plateletleukocyte aggregates in the effluent blood from flow chamber ex vivo, (Figure 2) closely resembling physiological conditions whereby activated platelets in circulation engage in thrombo-inflammatory associations with leukocytes. These results have been validated by assessing the impact of VUF11207 administration on circulatory platelet-leukocyte interactions $24 \mathrm{hrs}$ post-MI/RI and following carotid artery injury. VUF11207 administered mice show significantly reduced platelet-leukocyte aggregate formation in peripheral circulation post-MI and arterial injury [76]. Increased plasma levels of IL-6 supports platelet-monocyte interactions in ACS patients [88]. CXCR7-agonist administered mice also show significantly lower plasma levels of several inflammatory mediators (IL1 $\alpha$, IL1 $\beta$, TNF $\alpha$, IFN $\gamma$, IL-6, MCP-1) post-MI which suggests its therapeutic benefits. In vitro, pretreatment with VUF11207 reduces thrombo-inflammatory release from activated human and murine platelets [76]. The therapeutic potential of CXCR7-agonist in a profound thrombo-inflammatory disease setting like HIT is also commendable. HIT is a drug-induced adversity that may lead to venous/arterial thrombosis. Upon heparin administration in emergency, susceptible individuals may develop anti-PF4-heparin antibodies that activate platelets through Fc $\gamma$ RIIA, necessitating replacement of heparin. CXCR7-agonist not only counteracts HIT-IgG induced ex vivo activation of platelets (CD62P surface exposure, $\alpha_{\mathrm{Il}} \beta_{3}$-integrin activation, thrombus formation), and interferes with platelet response in heparin induced platelet aggregation (HIPA) test, but also retards the release of thrombo-inflammatory IL-1 $\beta$, IFN- $\gamma$, sCD40L, TNF- $\alpha$, sP-selectin, the neutrophil chemoattractant IL-8, and thrombogenic tissue factor from activated platelets. Neutrophils substantially aggravate HIT-associated thrombotic complications [77]. Neutrophils express ACKR3/CXCR7 [90,91], antagonism of which regulates pulmonary injury associated with acute inflammation [92]. However, we observed that CXCR7-agonist reduces HIT-IgG induced neutrophil activation, particularly activation of CD11b in the Mac- 1 complex. Thus, combined with its effect on platelet CD62P, CXCR7-agonist significantly reduces the formation of platelet-neutrophil aggregates triggered by HIT-IgG/sera [76]. These anti-thrombo-inflammatory attributes taken together suggests that therapeutics targeting ACKR3/CXCR7 may be effective in coping with HIT-associated thrombo- 
inflammation, also in acute inflammatory pathologies that trigger platelet Fc $\gamma$ RIIA, as recently exemplified by vaccine induced thrombotic thrombocytopenia-(VITT) [93] that closely resembles HIT, or antibodies generated in response to SARS-CoV2 infection $[82,86]$.

2.4.4 Unexpected influence of ACKR3/CXCR7 on the platelet lipidome: Mechanistic insights into the anti-thrombotic actions of ACKR3/CXCR7 reveals an unexpected influence on both basal and thrombin-activated platelet lipidome. ACKR3/CXCR7-ligation preferentially limits the metabolism and release of cyclcoxigenase (COX-1) (thromboxane A2-TXA2) and lipoxygenase (12-LOX) (12-hydroxyeicosatetraenoic acid, 12-HETE) derived pro-thrombotic oxylipins, and phospholipase derived atherogenic lipid mediators like lysophosphatidylcholine (LPCs), while favoring the generation of anti-platelet lipids like dihomo- $\gamma$-linolenic acid (DGLA) derived 12-hydroxyeicosatrienoic acid (12-HETrE) [94], docosahexaenoic acid (DHA) derived 13-Hydroxyoctadecadienoic acid (13HODE), eisocapentaenoic acid (EPA) derived 12-Hydroxyeicosapentaenoic acid (12-HEPE) [95]. Platelets from CAD patients show increased levels of oxidized phospholipids, ceramides, sphingomyelins, triglycerides, diacylglycerols (DG), LPCs, and lysophosphatidylinositol (LPIs), [63], notwithstanding anti-platelet or statin therapy $[76,96]$. CXCR7-agonist counters the generation arachidonic acid (AA), 12-hydroxyheptadecatrenoic acid (12-HHT), TxA2, 12-HETE, LPIs, and DGs from thrombin activated platelets of healthy subjects and CAD patients $e x$ vivo. This suggests the therapeutic potential of ACKR3/CXCR7 in regulating the generation of lipid agonists (AA, TxA2) that perpetuate platelet aggregation, or intracellular signaling intermediates (LPIs, DGs) that modulate the course and extent of platelet activation [76]. As a consequence, CXCR7-agonist reduces intraplatelet calcium mobilization, phosphorylation of effector kinases in the platelet activatory signaling cascade otherwise triggered by platelet stimulation. Such a unique influence of ACKR3/CXCR7 may check atherothrombosis by regulating the generation of pro-thrombotic and atherogenic lipids carried by platelets and platelet-derived microvesicles to the site of vascular injury or inflammation [97]. Future investigations will delineate the mechanistic basis behind this preference for 12-LOX, COX-1 and Cytp450 mediated metabolism of anti-platelet lipids, while limiting the generation of pro-thrombotic metabolites. 12-HETrE is a known anti-platelet mediator, which may be particularly effective in counteracting the actions of 12-LOX derived pro-thrombotic metabolite 12-HETE during platelet activation mediated through Fc $\gamma$ RIIA [94,98,99]. Attributed to 12-HETrE, atypical ACKR3/CXCR7-ligation coordinates with the G $\alpha$ s-coupled IP receptor to elevate platelet inhibitory cAMP levels; an effect contrary to the pro-thrombotic actions of Gai-coupled CXCR4 (Figure 1) $[59,63,64]$. Engagement of CXCR4 by CXCL12/SDF- $1 \alpha$ distinctively reduces platelet inhibitory cAMP levels to support platelet activation [59] while the anti-platelet effects of CXCR7-agonist are counteracted by IP-receptor antagonist and pharmacological inhibitors of the AC-cAMP-PKA pathway (Figure 3) [76]. This functional dichotomy between ACKR3/CXCR7 and CXCR4 (Figure 1) poses a unique physiological scenario whereby a balance between pro- and antithrombotic responses can be fine-tuned in CAD patients, in whom platelet surface expression of both CXCR4 and ACKR3/CXCR7 are enhanced. 


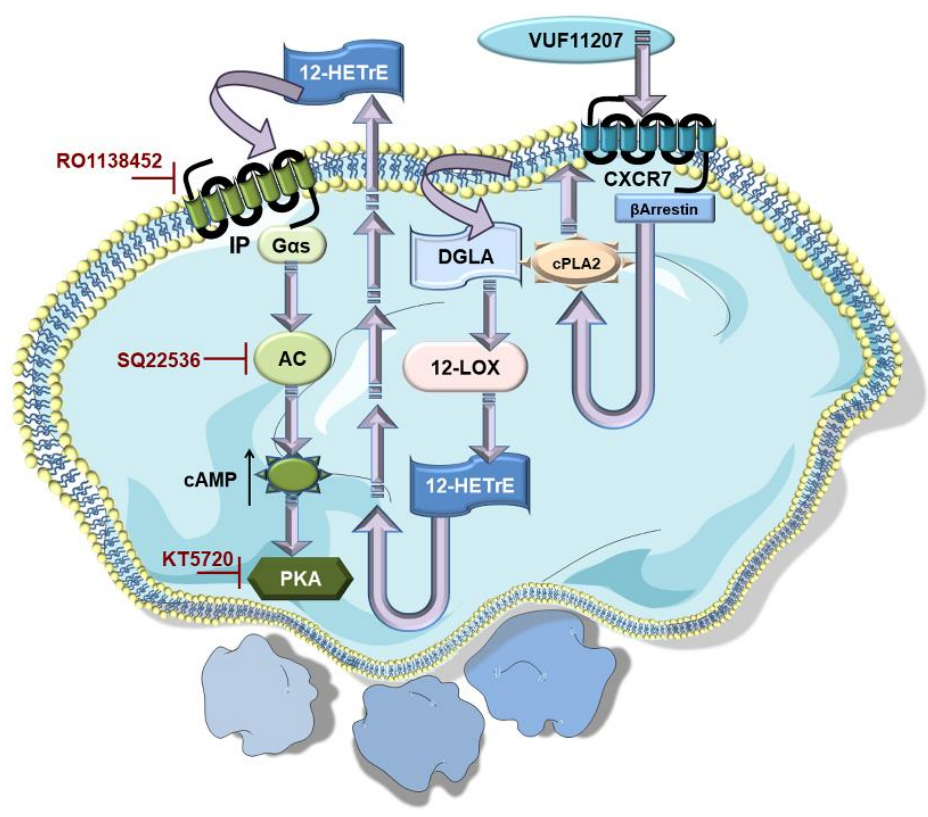

Figure 3. Non-canonical ACKR3/CXCR7 co-ordinates with canonical Gas-coupled IP-receptor to impose platelet inhibition. ACKR3/CXCR7-ligation by a pharmacological agonist (VUF11207) modulates the platelet lipidome, leading to an increased generation of anti-platelet lipid DGLA.12-LOX metabolizes DGLA into its anti-platelet oxylipin derivative 12-HETrE. 12-HETrE released in the microenvironment engages the Gas-coupled IP receptor on platelets. This triggers the platelet inhibitory AC-cAMP-PKA signaling cascade, as adenylyl cyclase is activated to elevate cAMP levels and triggers the downstream cyclic nucleotide dependent protein kinase A (PKA). Therefore, platelet inhibitory effects of CXCR7-agonist are reduced in the presence of pharmacological interventions in form of IP-receptor antagonist (RO1138452), AC (SQ22536), and PKA (KT5720) inhibitors.

\section{Therapeutic implication of ACKR3/CXCR7 in platelet associated cardiovascular disease}

Platelet-driven functional processes occupy an important niche in cardiovascular pathophysiology [4,5,7,80,81,100-102]. In recent years the functional involvement of ACKR3/CXCR7 in cardiovascular disease has been delineated using lineage specific receptor deficient mouse lines [26,27,103-105] (Table 1). Simultaneously, therapeutic implications of targeting ACKR3/CXCR7 $[45,106-108]$ using pharmacological agonists $[107,109,110]$ (Table 2) have been verified in atheroprogression $[103,111,112]$, which is intricately associated with inflammatory platelet functions; in arterial thrombosis [76]; in cerebral stroke [29,30,32,113-115], myocardial infarction and heart failure [26,27], diseases that are affected by thrombotic complications (Figure 4); also in pulmonary [104] and hepatic fibrosis [105]. To this effect, various pharmacological CXCR7-agonists have been employed e.g. cyclic-peptide-(TC14012) [104,109],[105], allosteric agonist-(AMD3100)[27],[110] ACKR3/CXCR7 specific CCX771 [103], and VUF11207 [76] demonstrating the therapeutic benefits of ACKR3/CXCR7 in functional recovery following myocardial infarction [27,28,76], in impeding pulmonary fibrosis [104], in promoting hepatic regeneration [105] and retarding atheroprogression [103] (Table 2 and Figure 4). Although most of these investigations did not address the direct impact of pharmacological CXCR7 agonists on platelet response as we have done recently[76], they certainly verified the regenerative implication of ACKR3/CXCR7 in the target organs or tissues that are infiltrated by activated platelets and influenced by platelet response.

Table 1. Relevance of ACKR3/CXCR7 in vascular pathophysiology.

\begin{tabular}{|c|c|c|c|c|}
\hline $\begin{array}{l}\text { (Cardio)vascular } \\
\text { pathophysiology }\end{array}$ & $\begin{array}{c}\text { Animal } \\
\text { models used }\end{array}$ & Mouse line & Functional evaluation & Ref. \\
\hline Atherosclerosis & $\begin{array}{l}\text { Wire injury of } \\
\text { carotid arteries }\end{array}$ & $\begin{array}{l}\text { CAG-CreER }{ }^{T M} C x c r 7^{\text {flox } / f l o x}, \\
\text { CAG-CreER }{ }^{T M} C x c r 7^{\text {flox/flox- }} \\
\text { Apoe }^{-/-} \text {(ubiquitous cxcr7 }\end{array}$ & $\begin{array}{l}\text { Increased neointima formation, } \\
\text { lesional macrophage accumulation } \\
\text { after vascular injury. }\end{array}$ & [103] \\
\hline
\end{tabular}




\begin{tabular}{|c|c|c|c|c|}
\hline & & deletion) & $\begin{array}{c}\text { Increased serum cholesterol } \\
\text { levels and hyperlipidemia-induced } \\
\text { monocytosis. }\end{array}$ & \\
\hline $\begin{array}{l}\text { Neointimal } \\
\text { hyperplasia }\end{array}$ & $\begin{array}{l}\text { Endothelial } \\
\text { denudation of the } \\
\text { femoral artery by } \\
\text { angioplasty wire } \\
\text { inflicted injury }\end{array}$ & $\begin{array}{c}C X C R 7^{\mathrm{f} / \mathrm{f}} C d h 5-C r e E R T 2^{+} \\
\text {conditional endothelial } \\
\text { cXcr7 knockout mice }\end{array}$ & $\begin{array}{l}\text { Increased neointimal hyperplasia and } \\
\text { neointima/media thickness ratio }\end{array}$ & [27] \\
\hline Angiogenesis & $\begin{array}{l}\text { Hind-limb } \\
\text { ischemia (femoral } \\
\text { artery ligation, laser } \\
\text { Doppler imaging) }\end{array}$ & $C X C R 7^{\mathrm{f} / \mathrm{f}} \mathrm{Cdh} 5-\mathrm{CreERT2}+$ & $\begin{array}{l}\text { Reduced blood flow recovery, reduced } \\
\text { vascular density in the ischemic } \\
\text { gastrocnemius }\end{array}$ & [27] \\
\hline $\begin{array}{l}\text { Pulmonary } \\
\text { fibrosis }\end{array}$ & $\begin{array}{l}\text { Acute and chronic } \\
\text { Intratracheal } \\
\text { administration of } \\
\text { bleomycin or } \\
\text { hydrochloric acid } \\
\end{array}$ & $\begin{array}{l}\text { VE-cadherin- } \\
\text { Cre } \\
\text { C } x \text { ERT2 } C x 7^{\mathrm{i} \triangle \mathrm{EEC} / \mathrm{i} \triangle \mathrm{LEC}}\end{array}$ & $\begin{array}{l}\text { Intra-tracheal instillation of TC14012 } \\
\text { reduces pulmonary fibrosis } \\
\text { (SMA, collagen I expression) and } \\
\text { notch signaling in control mice. }\end{array}$ & [104] \\
\hline $\begin{array}{l}\text { Pulmonary } \\
\text { inflammation }\end{array}$ & $\begin{array}{l}\text { Mice exposed to } \\
\text { nebulized LPS; } \\
\text { CXCR7 antagonist } \\
\text { CCX771 (10 mg/kg } \\
\text { body weight, s.c.) }\end{array}$ & C57BL/6 mice & $\begin{array}{l}\text { Reduced transepithelial migration, } \\
\text { release of neutrophil chemoattractant, } \\
\text { neutrophil MPO activity and oxidative } \\
\text { burst; decreased microvascular } \\
\text { permeability in treated mice }\end{array}$ & {$[91]$} \\
\hline Hepatic fibrosis & $\begin{array}{l}\text { Single and repeated } \\
\text { injections of } \mathrm{CCl}_{4} \text { for } \\
\text { acute and chronic in- } \\
\text { jury; bile duct } \\
\text { ligation induced } \\
\text { cholestasis model }\end{array}$ & $\begin{array}{c}\text { VE-cad- } \\
C r e^{E R T 2} \mathrm{C} x \mathrm{cr} 7^{\mathrm{loxP} / \mathrm{loxP}} \\
\text { Endothelial } \mathrm{cxcr} 7 \\
\text { knock out }\end{array}$ & $\begin{array}{l}\text { Impaired hepatic regeneration due to } \\
\text { diminished Id1-mediated generation } \\
\text { of angiocrine factors; increased fibrotic } \\
\text { response. }\end{array}$ & [105] \\
\hline \multirow{5}{*}{$\begin{array}{l}\text { Myocardial } \\
\text { infarction }\end{array}$} & $\begin{array}{l}\text { Permanent ligation } \\
\text { of the left anterior } \\
\text { descending (LAD) } \\
\text { coronary artery }\end{array}$ & $\begin{array}{c}C X C R 7{ }^{\mathrm{f} / \mathrm{f}} C d h 5-C r e E R T 2^{+} \\
\text {inducible endothelial } \\
\text { cxcr7 knockout mice }\end{array}$ & $\begin{array}{l}\text { Increased infarct size, reduced } \\
\text { vascular density at the infarcted } \\
\text { region, impaired cardiac function and } \\
\text { remodeling post-MI, increased } \\
\text { mortality }\end{array}$ & {$[27]$} \\
\hline & $\begin{array}{l}\text { Adenoviral delivery } \\
\text { of } c x c r 7 \text { via left } \\
\text { ventricle }\end{array}$ & C57BL/6 mice & $\begin{array}{l}\text { Decreased infarct size, improved } \\
\text { cardiac function }\end{array}$ & [27] \\
\hline & LAD ligation & $\begin{array}{c}\alpha \mathrm{MHC}-\mathrm{Cre}^{+/-} \\
\text {CXCR7flox/flox; cardiomy- } \\
\text { ocyte-specific } \mathrm{C} x \mathrm{cr} 7 \\
\text { knockout mice } \\
\end{array}$ & $\begin{array}{l}\text { Normal heart phenotype but promi- } \\
\text { nent left ventricular enlargement and } \\
\text { systolic dysfunction post MI }\end{array}$ & {$[26]$} \\
\hline & LAD ligation & $\begin{array}{l}\text { Col1a2-CreERT2 }{ }^{+-} \\
\text {CXCR7 flox/flox ; fibroblast- } \\
\text { specific knockout mice }\end{array}$ & $\begin{array}{c}\text { No significant reduction in heart } C x c r 7 \\
\text { expression, weight, left ventricular } \\
\text { volume, and systolic function under } \\
\text { basal condition or after MI }\end{array}$ & [26] \\
\hline & $\begin{array}{l}\text { LAD ligation for } 30 \\
\text { mins, MI/RI; } \\
\text { VUF11207 } \\
\text { (i.v. pre-MI) } \\
\end{array}$ & C57BL/6 mice & $\begin{array}{l}\text { Reduced infarct size, less } \\
\text { deteriorated LVEF } 24 \mathrm{hrs} \text { post MI/RI }\end{array}$ & {$[76]$} \\
\hline
\end{tabular}


3.1 Therapeutic potential of ACKR3/CXCR7 against atheroprogression: ACKR3/CXCR7 is richly expressed at the macrophage-enriched aortic atheroma of atherosclerosis prone apoe $e^{-/}$mice [111], and its expression is induced during human monocyte to macrophage differentiation [111] in vitro. Interestingly, atorvastatin exerting a pleiotropic effect independent of its cholesterol-lowering activity downregulates the expression of ACKR3/CXCR7 transcript in human THP-1 macrophages in vitro [112]. ACKR3/CXCR7 expression is observed in murine endothelial cells, which is significantly induced in the injured arteries and co-localizes with von Willebrand factor in neointimal endothelial cells. Similarly, CXCR7 expression is also observed in lesional endothelial cells of human aortic specimens. However, hyperlipidemic apoe-- mice ubiquitously and conditionally deficient in Cxcr7 show increased numbers of monocytes in circulation, distinctive neointimal hyperplasia and macrophage accumulation at carotid lesions; whereas administration of a pharmacological CXCR7-agonist from ChemoCentryx, CCX771, decreases neointimal area, monocytosis, accumulation of Mac2 ${ }^{+}$ macrophages at lesions, all of which contributes to ameliorate atheroprogression [103]. Apparently paradoxical, these findings heighten cell/tissue specific functional response under the regulatory influence of ACKR3/CXCR7. Administration of CCX771 for 4 weeks to hyperlipidemic mice reduces plasma levels of cholesterol by promoting the uptake of very low-density lipoproteins-(VLDL) but not LDL or high-density lipoprotein-(HDL) in the ACKR3/CXCR7 expressing white adipose tissue. CCX771 also increases lipoprotein lipase activity in the same by decreasing expression of the negative regulator of lipase activity Angpt14 [103]. Like the pharmacological agonist CCX771, CXCL12/SDF-1 $\alpha$ increases LDL and oxLDL uptake in platelets through active participation of both CXCR4 and ACKR3/CXCR7, since this process is counteracted by antibodies blocking either receptor. Treatment of platelets with oxLDL in vitro drives platelet activation, degranulation and surface exposure of CXCL12/SDF-1 $\alpha$, an internalization of CXCR4 but surface translocation of ACKR3/CXCR7. Therefore, intraplatelet oxLDL level, which is significantly enhanced in ACS patients, correlates positively with platelet ACKR3/CXCR7 surface expression but inversely with that of CXCR4 [63]. Although these clinical and experimental evidences are of great interest, the molecular mechanism driving ACKR3/CXCR7 influenced lipid uptake and lipase activity in tissue (e.g. adipose) and cellular systems (e.g. platelets) remains to be ascertained. Substantiating the observation from Christian Weber's group [103], subsequent investigators have also shown that both human and murine injured arteries show enhanced expression of ACKR3/CXCR7 among lesional endothelial cells, and endothelial cells of neointima respectively [27]. Moreover, genetic ablation of ACKR3/CXCR7 from the endothelial lineage in CXCR7f// Cdh5-CreERT2 ${ }^{+}$conditional knockout mice substantiates neointimal development following vessel injury, retards re-endothelialization and promotes atheroprogression [27].

Platelet-lipid or lipoprotein interactions may exert a significant impact in seeding atheroprogression $[63,65,116]$. Recently we have observed a regulatory influence of ACKR3/CXCR7 in modulating the platelet lipidome. Presence of pharmacological CXCR7-agonist VUF11207 limited the generation of phospholipase C derived LPCs [76] with distinct atherogenic properties. LPCs are a major constituent of activated platelet derived microvesicles. LPCs are richly deposited at atherosclerotic plaques, and demonstrated as a surrogate marker for plaque instability in hyperlipidemic $\left(\right.$ apo $\left.{ }^{-/}\right)$mice [97]. Enrichment of LPCs is also observed in human endarterectomy specimens from patients with symptomatic carotid artery stenosis. By acting through the receptor G2AR, LPCs can induce platelet activation (CD62P surface expression $\alpha_{\mathrm{IIb}} \beta_{3}$-integrin activation), and prompt formation of platelet-monocyte aggregates, thus bearing the potential to drive atherothrombotic complications. A limitation on thrombin-induced generation of LPCs as offered by CXCR7-agonist VUF11207 may be considered advantageous over aspirin which inhibits COX-1 downstream of phospholipases so that atherogenic LPCs can be generated and remain elevated in platelets from CAD patients despite anti-platelet and statin therapy $[63,76,96]$.

\subsection{Therapeutic efficacy of ACKR3/CXCR7 in limiting fibrosis and promoting tissue regeneration}

Platelets are involved in both reparative and fibrotic processes that follow tissue injury, having an array of soluble mediators ready to be unleashed from their granules. Substantial evidence from previous investigations point towards the regenerative inclination of ACKR3/CXCR7, while a more pro-fibrotic effect executed through CXCR4. Although a direct involvement and relative contribution of platelet CXCR4 and ACKR3/CXCR7 to such derogatory or reparative consequences remains to be seen, we can gain valuable insights from the available experimental and clinical evidences that have accumulated over the years as discussed in the context of myocardial, pulmonary and hepatic regeneration. 
Table 2. Currently available CXCR7-agonists for pre-clinical validation in cardiovascular disease.

\begin{tabular}{|c|c|c|c|}
\hline CXCR7 Agonist & Type & Tested therapeutic potential in & Ref. \\
\hline VUF11207 & $\begin{array}{l}\text { Small } \\
\text { molecule } \\
\text { agonist }\end{array}$ & $\begin{array}{l}\text { Platelet-inhibition; reduced arterial thrombosis } \\
\text { Reduced thrombo-inflammatory response post MI/RI, } \\
\text { arterial injury, that induced by HIT-IgG ex vivo } \\
\text { Reduced infarct size, less deteriorated LVEF post-MI }\end{array}$ & [76] \\
\hline $\begin{array}{c}\text { ChemoCentryx } \\
\text { CCX771 }\end{array}$ & $\begin{array}{l}\text { Small } \\
\text { molecule } \\
\text { agonist }\end{array}$ & $\begin{array}{l}\text { Reduced atheroprogression following vascular injury in } \\
\text { hyperlipidemic } A p o e^{-/-} \text {mice } \\
\text { Reduced serum cholesterol and triglyceride levels in hyper- } \\
\text { lipidemic } L d l r^{-/-} \text {mice }\end{array}$ & [103] \\
\hline TC14012 & $\begin{array}{l}\text { Cyclic } \\
\text { peptide } \\
\text { agonist }\end{array}$ & $\begin{array}{c}\text { Myocardial regeneration, function recovery post-MI } \\
\text { Neovascularization and myocardial regeneration post-MI } \\
\text { Reduced pulmonary fibrosis } \\
\text { Improved hepatic regeneration, reduced fibrosis }\end{array}$ & $\begin{array}{l}{[27]} \\
{[28]} \\
{[104]} \\
{[105]}\end{array}$ \\
\hline AMD3100 & $\begin{array}{l}\text { Small } \\
\text { molecule } \\
\text { allosteric } \\
\text { agonist }\end{array}$ & $\begin{array}{l}\text { Myocardial recovery post-MI } \\
\text { Reduced microglial activation, improved outcome } \\
\text { following experimental ischemic stroke }\end{array}$ & [117-119] \\
\hline
\end{tabular}

3.2.1 Myocardial regeneration and functional recovery: GPCRs have pivotal contribution in cardiac development and functioning in both health and disease [120]. Therapeutics targeting $\beta$-arrestinbiased signaling through $\beta$-adrenergic (e.g. carvedilol)[121] and angiotensin II receptors (e.g. TRV120067)[122], are cardioprotective agents applied in clinical practice or being validated in preclinical studies. The CXCL12/SDF-1-CXCR4-CXCR7 axis is long since recognized as a significant modulator of cardiac development, functioning, and repair. Both CXCR4 [123-125] and ACKR3/CXCR7 [126-130] are expressed by cardiomyocytes and exert complementary but differential influence on distinct aspects of cardiac development [131]. Cxcr7 is the most abundantly expressed seven pass transmembrane receptor gene in the murine heart and functions as a $\beta$-arrestinbiased receptor [26]. Cxcr7 mRNA levels are three-fold higher than those of the type 1A angiotensin II receptor (Agtr1a) and tenfold higher than those of the $\beta 1$-adrenergic receptor (Adrb1). Single-cell RNA-sequencing for 23 chemokine receptor transcripts in various cell types of the murine heart shows that ACKR3/CXCR7 is abundantly expressed in cardiomyocytes, and cardiac fibroblasts [26]. ACKR3/CXCR7 plays a critical role in cardiac development as its ubiquitous deletion in $\mathrm{Cxcr} 7^{-/-}$ mice causes postnatal lethality due to ventricular septal defects and malformation of the semilunar heart valve on account of diminished expression of factors essential for valve and vessel formation, growth and survival of endothelial cells [126]. Confirming this report, another group showed ACKR3/CXCR7 expression in murine cardiomyocytes, vascular endothelial cells of the lung and heart, the cerebral cortex and osteocytes, employing a LacZ reporter knock-in system. They also reported $70 \%$ postnatal lethality in $\mathrm{C} x \mathrm{cr} 7^{-/-}$mice within a week after birth. $\mathrm{C} x \mathrm{cr} 7^{-/-}$mice exhibit enlarged hearts, myocardial degeneration, postnatal fibrosis and hyperplasia of embryonic origin [130]. More recently smooth muscle specific ablation of $c x c r 7$ in SM22 $\alpha-C_{r e}{ }^{+}$CXCL12 ${ }^{\mathrm{f} / \mathrm{f}}$ mice has been reported to cause $50 \%$ perinatal mortality. Postnatally these mice develop severe fibrotic hypertrophy, show impaired cardiac function, also thin and dilated coronary arteries associated with diminished ACKR3/CXCR7 expression in the endothelial cells. However, pharmacological targeting of ACKR3/CXCR7 by administration of CXCR7-agonist TC14012 retards cardiac hypertrophy in these mice suggesting its therapeutic efficacy in counteracting adverse remodeling. TC14012 treated SM22 $\alpha$-Cre ${ }^{+}$CXCL12 ${ }^{\mathrm{ff} / \mathrm{f}}$ mice also show improvements in LVEF [132].

CXCR4 expression is increased in the infarct region following MI as established from PET/CT imaging studies in murine models and humans $[119,133]$. The cardioprotective effects of CXCR4 antagonist but allosteric CXCR7-agonist AMD3100 is well acknowledged in counteracting the actions of CXCL12/SDF-1 $\alpha$-CXCR4 axis during the acute phase of myocardial remodeling. AMD3100 reduces infarct size, non-infarcted left ventricular hypertrophy, improves systolic function $[117,134]$, and decreases scar expansion. Since CXCR4 regulates retention of progenitor cells in the 
bone marrow, CXCR4-antagonism by AMD3100 augments mobilization of bone marrow derived EPCs into circulation, their cardiac engraftment and EPC facilitated neovascularization. This reduces fibrosis and preserves myocardial function following MI [118,135,136]. In recent years the therapeutic benefits of CXCR7 specific agonist TC14012 [27,28] has also been demonstrated in improving myocardial regeneration and functional recovery following MI $[137,138]$.

Expression of ACKR3/CXCR7 is significantly increased at the infarct border zone than in the remote areas, along with concomitant activation induced phosphorylation of Erk, a signature signaling intermediate in the CXCL12/SDF-1 $\alpha$-CXCR7 pathway [26]. Single-cardiomyocyte RNA-seq results from human heart biopsies reveal increased CXCR7 expression in the cardiomyocytes of heart failure patients. This phenotype is reverted back to normal upon left ventricular assist device (LVAD) implantation in both ischemic and non-ischemic cardiomyopathies. These observations confirm the clinical relevance of ACKR3/CXCR7 in myocardial pathophysiology and the possibility of pre-clinical validation in murine models. This investigation further showed that cardiomyocytespecific deletion of $\mathrm{cxc} 7$ in $\alpha \mathrm{MHC}-\mathrm{Cre}^{+/-}$CXCR7flox/flox conditional knock out mice results in more prominent left ventricular enlargement and systolic dysfunction following MI [26]. Conditional deletion of $c x c r 7$ from the endothelial lineage in CXCR7/f/fCdh5-CreERT2 ${ }^{+}$mice also increases infarct size, causes functional impairment, reduces vascular density in the infarcted region and promotes fibrotic remodeling following MI [27]. The investigators have postulated that in the absence of ACKR3/CXCR7, circulatory CXCL12/SDF1 $\alpha$, although has regenerative attributes, could affect postMI cardiac remodeling [27] by engaging CXCR4, which is known to mediate fibrotic consequences. Targeted (adenoviral) delivery of $c x c r 7$ to the left ventricle and administration of CXCR7 agonist TC14012 [27] offers cardio-protective benefits. This therapeutic effect has been confirmed by other investigators using TC14012 [28], and recently by us using VUF11207 [76]. C57BL/6 J mice treated with TC14012 (i.p.) following MI enhances angiogenic response in ischemic heart tissue ascertained by increased expression of vWF, VEGFR2, p-SRC, p-PLC- $\gamma$ and the p-P38/t-P38 ratio. TC14012 counteracts the deterioration in cardiac function (e.g. ejection fraction and fractional shortening), and reduces infarct size after AMI [28]. Similarly, VUF11027 administered (i.v.) mice show reduced infarct size and less deteriorated LVEF 24hrs post-MI, concomitantly with reduced platelet-driven thrombotic response and thrombo-inflammatory platelet-leukocyte interaction in circulation [76]. However, systemic administration of VUF11207 may have exerted a significant impact on both the myocardium and peripheral blood cells, including platelets, which express ACKR3/CXCR7 and variously contribute to post-infarct myocardial recovery and remodeling [139-142]. Anti-platelet therapies targeting platelet COX-1 (aspirin), P12Y12 (clopidogrel, ticagrelor, prasugrel, cangrelor), GPIIbIIIa (abciximab, tirofiban, eptifibatide), GPVI (revacept),p-selectin (fucoidan, inclacumab) can exhibit pleotropic cardioprotective effects [5]. Novel theranostics in preclinical validation that target activated platelets to enrich delivery of cardioprotective drugs (Targ-CD39)[34,143] or progenitor cells (Tandem-scFvgPIIb/IIIa-Sca-1)[144] effectively combine diagnostic tools [145,146] and therapeutic prospects $[33,34,144]$ for myocardial regeneration and functional recovery. However, these innovative and clinical therapeutics exclusively target platelet receptors, while ACKR3/CXCR7 is broadly expressed in the ischiatic cardiac microenvironment, including infiltrating cells. Administration of VUF11207 pre-MI, counteracts subsequent platelet activation (p-selectin exposure, GPIIbIIIa activation) that influences platelet infiltration into the affected myocardium, thrombotic propensity and reduces platelet-leukocyte aggregates in circulation $24 \mathrm{hrs}$ post-MI, which may otherwise aggravate acute inflammatory processes following reperfusion. Yet, currently observed myocardial benefits of VUF11207 cannot be directly or entirely accredited to its anti-platelet action. The anti-thrombotic effects of VUF11207 possibly adds to its therapeutic value exerted directly on the myocardium post-MI [76], as previously demonstrated in case of TC14012 [27,28]since cardiomyocyte ACKR3/CXCR7 expression is increased. Further investigations are necessary to delineate the significance and involvement of platelet ACKR3/CXCR7 in modulating their interaction with other cellular components of the ischemic myocardium. To what extent platelet-ACKR3/CXCR7 may complement, override or impede the regenerative impact of cardiomyocyte-ACKR3/CXCR7 remains to be ascertained. Nevertheless, current investigations reinforce the therapeutic potential of ACKR3/CXCR7 in restoring the functionality of the affected myocardium, particularly since enhanced ACKR3/CXCR7 expression on both cardiomyocytes and circulating platelets offers a readily available therapeutic target.

3.2.2 Pulmonary fibrosis: In the hematopoietic-vascular niche of the lungs ACKR3/CXCR7 provides an in-built regenerative mechanism to prevent fibrosis following pulmonary injury. ACKR3/CXCR7 
is expressed in the pulmonary capillary endothelial cells (PCECs), actively prevents epithelial damage and retards fibrosis following a single phase intratracheal injection of bleomycin or hydrochloric acid. However, with repeated injury, ACKR3/CXCR7 expression is suppressed and the pro-fibrotic mechanism takes over, involving the recruitment of perivascular macrophages. This ensues a persistent upregulation of Notch signaling in the PCECs and perivascular fibroblasts to promote lung fibrosis. Incidentally, ACKR3/CXCR7 expression is also reduced in patients with interstitial pulmonary fibrosis [104]. Intratracheal administration of the CXCR7-agonist TC14012 following injury prevents alveolar epithelial damage and reduces pulmonary fibrosis. TC14012 counteracts pro-fibrotic response like $\beta$-catenin-dependent induction of Notch ligand Jag1 expression in PCECs, and Hes1 in pulmonary fibroblasts, also amends increased levels of $\alpha$-smooth muscle actin (SMA) and collagen I synthesis in the injured lung [104].

The thrombo-inflammatory impact of platelets in respiratory diseases is well investigated and characterized; whether in acute infectious pulmonary diseases inflicted by Streptococcus pneumoniae $[147,148]$, Pseudomonas aeruginosa [149], influenza A virus H1N1 (A/H1N1) [150,151], severe acute respiratory syndrome coronavirus 2 (SARS-CoV-2) [85-87] or chronic respiratory diseases like asthma [152,153], chronic obstructive pulmonary disease (COPD) [154] and aspirin exacerbated respiratory disease (AERD) [155]. Platelet derived inflammatory mediators, platelet interaction with inflammatory cells of the innate (monocyte, neutrophils) or the adaptive immune wing play a decisive role in disease progression and severity [156]. Some of these pathologies involve platelet activation through Fc $\gamma$ RIIa as an effector mechanism in instigating thrombo-inflammatory response $[85,86]$; while platelet derived $\mathrm{TxA}_{2}$ may induce bronchoconstriction [157] and cysteinyl leukotrienes produced during transcellular lipid metabolism involving platelets and leukocytes [158] can exaggerate the inflammatory processes. The link between inflammation and thrombosis is infallible in cardiovascular disease. Impact of anti-platelet therapies on circulatory inflammatory mediators like hsCRP, IL-6, TNF- $\alpha$ has been deduced in clinical studies [80]. Anti-platelet therapeutics like cangrelor is effective against pulmonary fibrosis in murine model [159]. Given the already recognized influence of CXCR7-agonist in ameliorating pulmonary fibrosis [104], its recently discovered efficacy in governing thrombo-inflammatory platelet-leukocyte interactions, and its regulation on the generation of thrombo-inflammatory lipids (e.g. TxA2, 12-HETE) (Blood), the anti-platelet significance of ACKR3/CXCR7 deserves a closer look in chronic and acute pulmonary inflammation.

3.2.3 Hepatic regeneration: The commendable regenerative potential of the liver [160] may be surmounted by a fibrotic response following chronic and acute hepatic inflammation or injury that can eventually lead to hepatic cirrhosis and failure [161-163]. The hepatic vascular niche includes liver sinusoidal endothelial cells (LSECs), which are primarily responsible for regeneration [160] through release of angiocrine factors, whereas the non-parenchymal hepatic stellate cells (HSC) mediate extracellular matrix deposition leading to fibrosis [163]. As observed for platelets [76], a striking functional dichotomy of CXCR4-CXCR7 has been demonstrated in balancing the regenerative as opposed to fibrotic phenotype of LSECs following acute and chronic liver injury [105]. The transition from a regenerative to a pro-fibrotic hepato-vascular niche involves differential expression of ACKR3/CXCR7 and CXCR4 in LSECs. Acute hepatic injury inflicted by carbon tetrachloride $\left(\mathrm{CCl}_{4}\right)$ and acetaminophen causes upregulation in the expression and functional engagement of CXCR4, ACKR3/CXCR7 in LSEC that triggers generation of regenerative angiocrine factors. ACKR3/CXCR7 expression is primarily upregulated in VE-cadherin+ LSECs, whereas CXCR4 is stably and broadly expressed by different cell types. Both physiological (CXCL12/SDF-1 $\alpha$ ) and pharmacological (TC14102) CXCR7-agonists induce expression of the transcription factor-Id1 in cultured LSECs. Moreover, inducible endothelial deletion of $c x c r 7$ in LSECs of CXcr7 ${ }^{\mathrm{AEC} / \mathrm{i} \triangle \mathrm{EC}}$ mice impairs liver regeneration by decreasing Id1-induced production of angiocrine factors. However, chronic insult with repetitive hepatotoxin (carbon tetrachloride) injection and bile duct ligation increases CXCR4 expression, as the pro-fibrotic FGFR1/CXCR4 angiocrine pathway counters the regenerative potential of ACKR3/CXCR7. Levels of pro-fibrotic $\alpha$-SMA and collagen are particularly elevated in the absence of $c x c r 7$ from the endothelial lineage in $C x{ }^{2} 7^{\mathrm{i} \triangle \mathrm{EC} / \mathrm{C} \triangle \mathrm{EC}}$ mice. Administration of CXCR7-agonist TC14102 retards these pro-fibrotic changes demonstrating its therapeutic potential to ameliorate hepatic fibrosis and promote regenerative mechanisms [105]. Another investigation employing partial hepatectomy model in rats demonstrated that expression of CXCL12/SDF- $1 \alpha$ is significantly upregulated in LSECs which mediates proliferation, mobilization, and engraftment of ACKR3/CXCR7 ${ }^{+}$ progenitors of LSECs to facilitate hepatic regeneration [164]. 
Platelets have a very close association with the pathophysiological functioning of the liver $[165,166]$, since both platelet biogenesis and clearance of senescent platelets are influenced or operated by cellular systems in the liver [167]. Liver parenchymal and sinusoidal endothelial cells synthesize and release the hormone thrombopoietin (TPO), which boosts megakaryopoiesis to generate platelets, while hepatic malfunctioning in diverse liver-related pathologies is associated with a drop in circulatory platelet count. Platelets on the other hand contribute to the maintenance of physiological hemostasis and vascular integrity by acting as sentinels detecting liver infection, inflammation and injury. Platelets actively contribute to several liver pathologies [168] including nonalcoholic fatty liver diseases [169], liver inflammation and hepatitis [170]. Platelet derived functionally opposing fibrotic (serotonin-5-HT, sphingosine-1-phosphate, platelet factor 4-CXCL4) and anti-fibrotic (ADP, ATP, hepatocyte growth factor) granular releasate can regulate the propensity of hepatic stellate cells to synthesize extracellular matrix components like collagen I and II, or retard the process respectively; besides promote fibrinolysis by enhancing matrix-metalloproteinase (MMP) activity [165]. Platelets are recruited to LSECs following chemical injury (CCl4) or hepatectomy. Platelet derived CXCL12/SDF-1 $\alpha$ stimulates ACKR3/CXCR7 ${ }^{+}$liver LSECs and contribute to hepatic regeneration by inducing the production of pro-regenerative angiocrine Wnt2 and HGF. This process is impaired in thrombopoietin-deficient $\mathrm{Thpo}^{-/-}$mice with suppressed circulatory platelet counts and following induced deletion of $C x c r 7$ in LSEC of $C x c r 7^{\mathrm{i} \Delta / \mathrm{i} \Delta}$ mice [171]. The contribution of platelet ACKR3/CXCR7 in influencing their interaction with the hepatic microenvironment is warranting. ACKR3/CXCR7 being a prosurvival receptor for platelets, research in this direction might reveal valuable insights into the hepatic trigger for platelet biogenesis and clearance of aged platelets in the hepatic vascular niche, besides modulating their active participation in hepatic regeneration and immune surveillance.

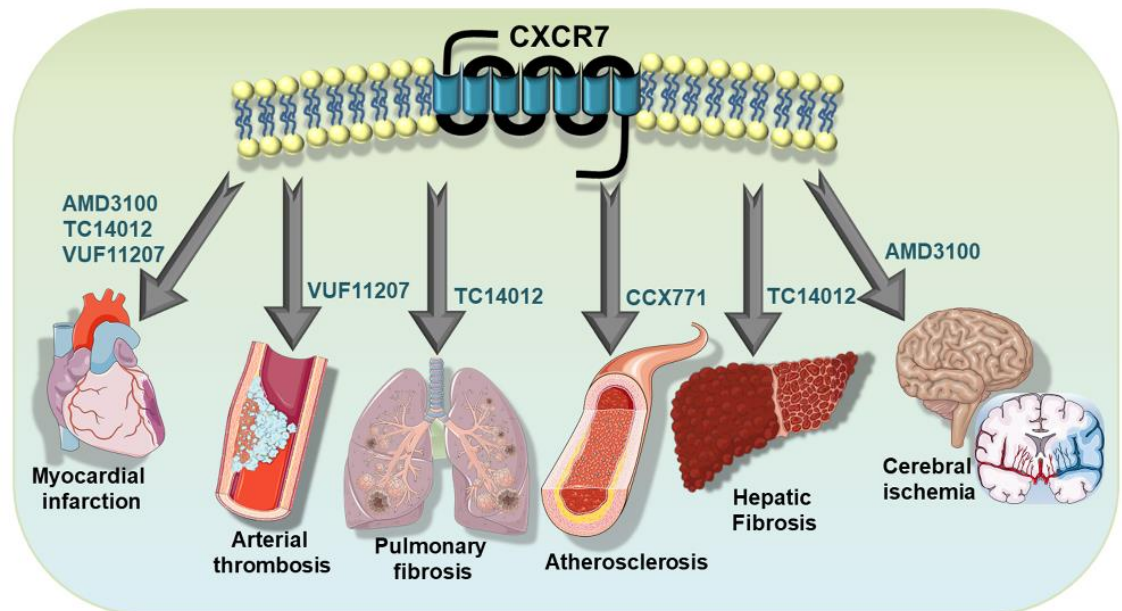

Figure 4. Therapeutic implementation of ACKR3/CXCR7 in platelet associated pathologies. Therapeutic potential of ACKR3/CXCR7 has been demonstrated using pharmacological agonists in disease models of atheroprogression, arterial thrombosis, myocardial infarction, cerebral stroke, in impeding pulmonary fibrosis and promoting hepatic regeneration.

\section{Discussion}

\section{ACKR3/CXCR7 as an anti-thrombotic drug target: considering the pros and cons}

Anti-platelet therapies like aspirin, $\mathrm{P}_{2} \mathrm{Y}_{12}$-antagonists, are cornerstone in prevention and secondary management of platelet hyper-reactivity that frequently leads to recurrent thrombo-ischemic complications in ACS patients [172]. Better anti-thrombotic strategies are required to overcome the drawbacks of current therapeutics, which are manifested as increased bleeding complications upon prolonged use, or refractoriness to optimal therapeutic benefits $[173,174]$.

Platelet surface expression of ACKR3/CXCR7 is low under physiological conditions [37,40], which can be dynamically altered in the presence of CXCL12/SDF1- $\alpha$. However, levels of pro-inflammatory mediators like CXCL12/SDF1- $\alpha$ and MIF are also low under physiological conditions, and therefore unlikely to alter ACKR3/CXCR7 surface availability or trigger ACKR3/CXCR7 mediated regulatory effects. But plasma levels of CXCL12/SDF1- $\alpha[12,38]$ and MIF [44] are elevated in CAD patients, which combined with increased surface availability of both CXCR4 and ACKR3/CXCR7 on platelets $[23,25]$ may decide on the balance between pro- and anti-thrombotic 
functions. ACKR3/CXCR7 does not play an active role in mediating thrombotic-hemostatic platelet response like other GPCRs e.g. PARs, $\mathrm{P}_{2} \mathrm{Y}_{12}, \mathrm{P}_{2} \mathrm{Y}_{1}$, which are engaged by platelet activating stimuli thrombin and ADP, respectively. To date there is no experimental evidence suggesting a potential crosstalk between ACKR3/CXCR7 and platelet receptors that either execute thrombotic response, i.e. the major glycoproteins-GPI, GPV, GPVI, GPIX, the PARs, purinergic receptors, or those that inhibit platelet function, i.e. immunoreceptor tyrosine-based inhibitory motif (ITIM) bearing receptors. In vivo administration of CXCR7-agonist (VUF11207) does not affect the surface availability of GPIb, GPV, GPVI, GPIX, $\alpha_{\mathrm{v}}-\beta 3$-integrin on murine platelets [76]. Currently do we have any reason to speculate that ACKR3/CXCR7 may directly sequester or influence ligand binding to any of these receptors. Although, as a high affinity "decoy" receptor, ACKR3/CXCR7 may sequester and degrade CXCL12/SDF1- $\alpha$ [108,175-180], preventing its pro-thrombotic actions through CXCR4 $[15,21,59,64]$ : but then again, levels of CXCL12/SDF1- $\alpha$, and platelet surface expression of ACKR3/CXCR7, both are low under physiological conditions. Taking these possibilities into consideration it is evident that any regulatory influence mediated through ACKR3/CXCR7 on platelet surface can only be triggered in the presence of a receptor specific inflammatory (CXCL11, CXCL12/SDF1- $\alpha$, MIF) or pharmacological ligand, and that genetic deletion of ACKR3/CXCR7 might not affect basal platelet responsiveness or exhibit a striking platelet-centered phenotype in vivo. Nevertheless, unlike anti-platelet drugs in clinical practice, ACKR3/CXCR7 offers us the possibility of fine-tuning platelet response without interfering with the availability or functionality of receptors that sense vascular damage/alterations (GPIb, GPV, GPVI, GPIX) or those that mediate physiological hemostasis (e.g. integrins, PARs, $\mathrm{P}_{2} \mathrm{Y}_{12}$ ).

The known physiological ligands of ACKR3/CXCR7 are either pro-inflammatory chemokines (CXCL11/ITAC, CXCL12/SDF-1 $\alpha$ ), cytokines (MIF) or adrenomedullin, therefore cannot be intended for therapeutic purposes. To date a number of ACKR3/CXCR7 agonists have been invented including peptide agonists, cyclic peptides, small molecule agonists and even orally available natural agonist [181] that exhibit different degrees of specificity (Table 2), and affinity for ACKR3/CXCR7 [106-108,182,183]. Use of these agonists for preclinical validation of ACKR3/CXCR7 as an anti-platelet drug target is definitely plausible. Some of these agonists are convincingly effective in ameliorating cardio/cerebrovascular complications [26-28,103] and vascular pathologies (Figure 4). However, currently available ACKR3/CXCR7 agonists or those in development will have to consider the following aspects and not just pharmacologic, pharmacokinetic and regulatory toxicological measures, before their translational implementation as an anti-platelet therapy in clinical practice-

- ACKR3/CXCR7 is ubiquitously expressed to various extent by circulating immune (monocytes, macrophages, [28] T-lymphocytes [184], B-lymphocytes [185], neutrophils [90-92]) and vascular cells (endothelium [27]), also cells constituting the target organs these blood vessels perfuse (e.g. myocardium [26], brain [30,32,186,187]). Therefore, ACKR3/CXCR7 may elicit cell and organ specific functional response [45], which cannot be restricted specifically to platelets. This necessitates thorough functional characterization of anticipated cellular targets under the influence of a CXCR7-agonist, to prevent undesirable off-target deleterious effects other than the one intended as an anti-platelet agent.

- It is absolutely essential to consider that ACKR3/CXCR7 exhibits ligand specific functional response [188] even in platelets. Although CXCL11, CXCL12/SDF1- $\alpha$, MIF execute an anti-apoptotic effect through ACKR3/CXCR7, only MIF demonstrates an anti-thrombotic influence [37,40], although without affecting other platelet functions like spreading, degranulation, aggregation [74,75]. CXCL12/SDF1- $\alpha$ evidently promotes a pro-thrombotic response but through CXCR4 $[21,59,64]$. Such discrepancies may arise due to ligand specific conformational changes upon ACKR3/CXCR7 engagement [188]. A pharmacological CXCR7-agonist intended as an anti-platelet agent will have to be validated for several platelet functions, their interaction with circulatory and vascular cells, and those in the organs (e.g. myocardium) that are infiltrated by activated platelets $[5,7,34]$, to fully apprehend its scope for therapeutic application in cardiovascular pathologies.

- Needless to say, that a detailed mechanistic insight into the anti-platelet mode of action is mandatory to convincingly attribute the observed anti-thrombotic benefits of existing CXCR7-agonists (Table 2) $[106,107,109,110,183]$ or those in development, to be specifically mediated through ACKR3/CXCR7 and not as a pleiotropic effect. 
- Over $90 \%$ of publications concerning ACKR3/CXCR7 enlisted in PubMed stem from research in the context of various cancers, where ACKR3/CXCR7 has been shown to play a decisive role in cancer progression, angiogenesis and even prognostic outcome [45,189-191]. Given the level of our current scientific understanding on ACKR3/CXCR7, it is perhaps neither advisable nor reasonable to continuously trigger this receptor by prolonged use of an agonist. Therefore, it is essential to ascertain the therapeutic 'time-window' during which availability of ACKR3/CXCR7 is observed as a potential anti-platelet drug target in cardiovascular diseases, and to categorically define a dosage and treatment regimen. Our aim should be to utilize the therapeutic benefits of ACKR3/CXCR7 agonist as an anti-thrombotic agent without inflicting neoplastic changes; and while doing so to substantiate functional recovery of the afflicted organs (e.g. myocardium) following thrombo-inflammatory and thrombo-ischemic damage, as effectively demonstrated for myocardial infarction $[27,28,76]$. The prospect of ligand and cell specific response, also biased signaling through ACKR3/CXCR7 can be exploited to fulfill this objective. However, fundamental research on the molecular mechanisms driving signaling events and functional response downstream of ACKR3/CXCR7 needs to be attended to in parallel to translational research initiatives to make productive progress in this direction.

\section{Conclusions and future directions}

Considering the versatile involvement of ACKR3/CXCR7 driving miscellaneous cellular response in diverse pathologies and the multifaceted molecular pathways triggered [192], it is undoubtedly a challenging GPCR to work with. Some investigations have presented conflicting evidences on- its expression or the lack of it in circulatory cells [193]. Its role has been defined merely as a "decoy receptor" for CXCL12/SDF1- $\alpha$ to a functional signaling receptor actively engaged in cellular growth, differentiation, survival, inflammation, and neoplastic transformation. Its involvement has been depicted in mediating various processes of tissue and organ regeneration $[45,90,106,108,194]$. The controversy about its restriction to atypical or non-canonical G protein independent actions $[175,195,196]$, its potential to heterodimerize with and regulate canonical actions of CXCR4 [192] have further added to the challenges in delineating the molecular mechanisms instigated exclusively by ACKR3/CXCR7. No wonder, less than 900 articles are retrieved in PubMed till date with the keyword "CXCR7", since its discovery in 2005 [197]. Nevertheless, gathering evidence on the therapeutic implication of ACKR3/CXCR7 in atherosclerosis [103], myocardial infarction [27,28], pulmonary fibrosis [104], hepatic regeneration [105], its role in platelet pathophysiology and CAD [23-25,63] cannot be overlooked. Therefore, surmounting the challenges of investigating ACKR3/CXCR7 in experimental, preclinical and clinical studies possibly ensures an encouraging translational outcome.

Author Contributions: Concept of the review, writing, illustrations: M. Chatterjee.

Funding: Funding support from German Research Foundation DFG-Project number 374031971TRR240, and Deutsche Stiftung für Herzforschung (DSHF-F/22/17) to M. Chatterjee.

Acknowledgments: Illustrations were prepared with the help of Servier Medical Art https://smart.servier.com

Conflicts of Interest: "The author declares no conflict of interest."

\section{References}

1. McFadyen, J.D.; Schaff, M.; Peter, K. Current and future antiplatelet therapies: emphasis on preserving haemostasis. Nat Rev Cardiol 2018, 15, 181-191, doi:10.1038/nrcardio.2017.206.

2. Rayes, J.; Bourne, J.H.; Brill, A.; Watson, S.P. The dual role of platelet-innate immune cell interactions in thromboinflammation. Res Pract Thromb Haemost 2020, 4, 23-35, doi:10.1002/rth2.12266.

3. Coenen, D.M.; Heinzmann, A.C.A.; Karel, M.F.A.; Cosemans, J.; Koenen, R.R. The multifaceted contribution of platelets in the emergence and aftermath of acute cardiovascular events. Atherosclerosis 2021, 319, 132-141, doi:10.1016/j.atherosclerosis.2020.12.017. 
4. van der Meijden, P.E.J.; Heemskerk, J.W.M. Platelet biology and functions: new concepts and clinical perspectives. Nat Rev Cardiol 2019, 16, 166-179, doi:10.1038/s41569-018-0110-0.

5. Ziegler, M.; Wang, X.; Peter, K. Platelets in cardiac ischaemia/reperfusion injury: a promising therapeutic target. Cardiovasc Res 2019, 115, 1178-1188, doi:10.1093/cvr/cvz070.

6. McFadyen, J.D.; Peter, K. Novel Antithrombotic Drugs on the Horizon: The Ultimate Promise to Prevent Clotting While Avoiding Bleeding. Circ Res 2017, 121, 1133-1135, doi:10.1161/CIRCRESAHA.117.312012.

7. Walsh, T.G.; Poole, A.W. Do platelets promote cardiac recovery after myocardial infarction: roles beyond occlusive ischemic damage. Am J Physiol Heart Circ Physiol 2018, 314, H1043-H1048, doi:10.1152/ajpheart.00134.2018.

8. Chatterjee, M.; Geisler, T. Inflammatory Contribution of Platelets Revisited: New Players in the Arena of Inflammation. Semin Thromb Hemost 2016, 42, 205-214, doi:10.1055/s-0035-1570081.

9. Prabhu, S.D.; Frangogiannis, N.G. The Biological Basis for Cardiac Repair After Myocardial Infarction: From Inflammation to Fibrosis. Circ Res 2016, 119, 91-112, doi:10.1161/CIRCRESAHA.116.303577.

10. Walsh, T.G.; Poole, A.W. Platelets Protect Cardiomyocytes from Ischaemic Damage. TH Open 2017, 1, doi:10.1055/s-00371603928.

11. Meyer, A.; Wang, W.; Qu, J.; Croft, L.; Degen, J.L.; Coller, B.S.; Ahamed, J. Platelet TGF-beta1 contributions to plasma TGFbeta1, cardiac fibrosis, and systolic dysfunction in a mouse model of pressure overload. Blood 2012, 119, 1064-1074, doi:10.1182/blood-2011-09-377648.

12. Geisler, T.; Fekecs, L.; Wurster, T.; Chiribiri, A.; Schuster, A.; Nagel, E.; Miller, S.; Gawaz, M.; Stellos, K.; Bigalke, B. Association of platelet-SDF-1 with hemodynamic function and infarct size using cardiac MR in patients with AMI. Eur $J$ Radiol 2012, 81, e486-490, doi:10.1016/j.ejrad.2011.06.019.

13. Stellos, K.; Langer, H.; Daub, K.; Schoenberger, T.; Gauss, A.; Geisler, T.; Bigalke, B.; Mueller, I.; Schumm, M.; Schaefer, I., et al. Platelet-derived stromal cell-derived factor-1 regulates adhesion and promotes differentiation of human CD34+ cells to endothelial progenitor cells. Circulation 2008, 117, 206-215, doi:10.1161/CIRCULATIONAHA.107.714691.

14. Stellos, K.; Seizer, P.; Bigalke, B.; Daub, K.; Geisler, T.; Gawaz, M. Platelet aggregates-induced human CD34+ progenitor cell proliferation and differentiation to macrophages and foam cells is mediated by stromal cell derived factor 1 in vitro. Semin Thromb Hemost 2010, 36, 139-145, doi:10.1055/s-0030-1251497.

15. Chatterjee, M.; Gawaz, M. Platelet-derived CXCL12 (SDF-1alpha): basic mechanisms and clinical implications. J Thromb Haemost 2013, 11, 1954-1967, doi:10.1111/jth.12404.

16. Chatterjee, M.; von Ungern-Sternberg, S.N.; Seizer, P.; Schlegel, F.; Buttcher, M.; Sindhu, N.A.; Muller, S.; Mack, A.; Gawaz, M. Platelet-derived CXCL12 regulates monocyte function, survival, differentiation into macrophages and foam cells through differential involvement of CXCR4-CXCR7. Cell Death Dis 2015, 6, e1989, doi:10.1038/cddis.2015.233.

17. Stellos, K.; Bigalke, B.; Langer, H.; Geisler, T.; Schad, A.; Kogel, A.; Pfaff, F.; Stakos, D.; Seizer, P.; Muller, I., et al. Expression of stromal-cell-derived factor- 1 on circulating platelets is increased in patients with acute coronary syndrome and correlates with the number of CD34+ progenitor cells. Eur Heart J 2009, 30, 584-593, doi:10.1093/eurheartj/ehn566.

18. Stellos, K.; Bigalke, B.; Borst, O.; Pfaff, F.; Elskamp, A.; Sachsenmaier, S.; Zachmann, R.; Stamatelopoulos, K.; Schonberger, T.; Geisler, T., et al. Circulating platelet-progenitor cell coaggregate formation is increased in patients with acute coronary syndromes and augments recruitment of CD34+ cells in the ischaemic microcirculation. Eur Heart J 2013, 34, 2548-2556, doi:10.1093/eurheartj/eht131.

19. Stellos, K.; Gawaz, M. Platelet interaction with progenitor cells: potential implications for regenerative medicine. Thromb Haemost 2007, 98, 922-929, doi:10.1160/th07-02-0147.

20. Stellos, K.; Gawaz, M. Platelets and stromal cell-derived factor-1 in progenitor cell recruitment. Semin Thromb Hemost 2007, 33, 159-164, doi:10.1055/s-2007-969029. 
21. Chatterjee, M.; Rath, D.; Gawaz, M. Role of chemokine receptors CXCR4 and CXCR7 for platelet function. Biochem Soc Trans 2015, 43, 720-726, doi:10.1042/BST20150113.

Wurster, T.; Stellos, K.; Haap, M.; Seizer, P.; Geisler, T.; Otton, J.; Indermuehle, A.; Ishida, M.; Schuster, A.; Nagel, E., et al. Platelet expression of stromal-cell-derived factor-1 (SDF-1): an indicator for ACS? Int J Cardiol 2013, 164, 111-115, doi:10.1016/j.ijcard.2011.06.082.

23. Rath, D.; Chatterjee, M.; Borst, O.; Muller, K.; Stellos, K.; Mack, A.F.; Bongartz, A.; Bigalke, B.; Langer, H.; Schwab, M., et al. Expression of stromal cell-derived factor-1 receptors CXCR4 and CXCR7 on circulating platelets of patients with acute coronary syndrome and association with left ventricular functional recovery. Eur Heart J 2014, 35, 386-394, doi:10.1093/eurheartj/eht448.

24. Rath, D.; Chatterjee, M.; Meyer, L.; Tekath, N.; Olma, C.; Krumm, P.; Adams, C.; Borst, O.; Muller, K.; Droppa, M., et al. Relative survival potential of platelets is associated with platelet CXCR4/CXCR7 surface exposure and functional recovery following STEMI. Atherosclerosis 2018, 278, 269-277, doi:10.1016/j.atherosclerosis.2018.10.008.

25. Rath, D.; Chatterjee, M.; Borst, O.; Muller, K.; Langer, H.; Mack, A.F.; Schwab, M.; Winter, S.; Gawaz, M.; Geisler, T. Platelet surface expression of stromal cell-derived factor-1 receptors CXCR4 and CXCR7 is associated with clinical outcomes in patients with coronary artery disease. J Thromb Haemost 2015, 13, 719-728, doi:10.1111/jth.12870.

Ishizuka, M.; Harada, M.; Nomura, S.; Ko, T.; Ikeda, Y.; Guo, J.; Bujo, S.; Yanagisawa-Murakami, H.; Satoh, M.; Yamada, S., et al. CXCR7 ameliorates myocardial infarction as a beta-arrestin-biased receptor. Sci Rep 2021, 11, 3426, doi:10.1038/s41598021-83022-5.

27. Hao, H.; Hu, S.; Chen, H.; Bu, D.; Zhu, L.; Xu, C.; Chu, F.; Huo, X.; Tang, Y.; Sun, X., et al. Loss of Endothelial CXCR7 Impairs Vascular Homeostasis and Cardiac Remodeling After Myocardial Infarction: Implications for Cardiovascular Drug Discovery. Circulation 2017, 135, 1253-1264, doi:10.1161/CIRCULATIONAHA.116.023027.

28. Zhang, S.; Yue, J.; Ge, Z.; Xie, Y.; Zhang, M.; Jiang, L. Activation of CXCR7 alleviates cardiac insufficiency after myocardial infarction by promoting angiogenesis and reducing apoptosis. Biomed Pharmacother 2020, 127, 110168, doi:10.1016/j.biopha.2020.110168.

29. Zhang, Y.; Zhang, H.; Lin, S.; Chen, X.; Yao, Y.; Mao, X.; Shao, B.; Zhuge, Q.; Jin, K. SDF-1/CXCR7 Chemokine Signaling is Induced in the Peri-Infarct Regions in Patients with Ischemic Stroke. Aging Dis 2018, 9, 287-295, doi:10.14336/AD.2017.1112.

30. Dong, B.C.; Li, M.X.; Wang, X.Y.; Cheng, X.; Wang, Y.; Xiao, T.; Jolkkonen, J.; Zhao, C.S.; Zhao, S.S. Effects of CXCR7neutralizing antibody on neurogenesis in the hippocampal dentate gyrus and cognitive function in the chronic phase of cerebral ischemia. Neural Regen Res 2020, 15, 1079-1085, doi:10.4103/1673-5374.270416.

31. Zhang, J.; Zhang, Y.; Xin, S.; Wu, M.; Zhang, Y.; Sun, L. CXCR7 suppression modulates macrophage phenotype and function to ameliorate post-myocardial infarction injury. Inflamm Res 2020, 69, 523-532, doi:10.1007/s00011-020-01335-z.

32. Cheng, X.; Wang, H.; Zhang, X.; Zhao, S.; Zhou, Z.; Mu, X.; Zhao, C.; Teng, W. The Role of SDF-1/CXCR4/CXCR7 in Neuronal Regeneration after Cerebral Ischemia. Front Neurosci 2017, 11, 590, doi:10.3389/fnins.2017.00590.

33. Ziegler, M.; Wang, X.; Lim, B.; Leitner, E.; Klingberg, F.; Ching, V.; Yao, Y.; Huang, D.; Gao, X.M.; Kiriazis, H., et al. PlateletTargeted Delivery of Peripheral Blood Mononuclear Cells to the Ischemic Heart Restores Cardiac Function after IschemiaReperfusion Injury. Theranostics 2017, 7, 3192-3206, doi:10.7150/thno.19698.

34. Ziegler, M.; Hohmann, J.D.; Searle, A.K.; Abraham, M.K.; Nandurkar, H.H.; Wang, X.; Peter, K. A single-chain antibodyCD39 fusion protein targeting activated platelets protects from cardiac ischaemia/reperfusion injury. Eur Heart J 2018, 39, 111-116, doi:10.1093/eurheartj/ehx218.

35. Chen, D.; Xia, Y.; Zuo, K.; Wang, Y.; Zhang, S.; Kuang, D.; Duan, Y.; Zhao, X.; Wang, G. Crosstalk between SDF-1/CXCR4 and SDF-1/CXCR7 in cardiac stem cell migration. Sci Rep 2015, 5, 16813, doi:10.1038/srep16813. 
36. Cao, Z.; Tong, X.; Xia, W.; Chen, L.; Zhang, X.; Yu, B.; Yang, Z.; Tao, J. CXCR7/p-ERK-Signaling Is a Novel Target for Therapeutic Vasculogenesis in Patients with Coronary Artery Disease. PLoS One 2016, 11, e0161255, doi:10.1371/journal.pone.0161255.

37. Chatterjee, M.; Seizer, P.; Borst, O.; Schonberger, T.; Mack, A.; Geisler, T.; Langer, H.F.; May, A.E.; Vogel, S.; Lang, F., et al. SDF-1alpha induces differential trafficking of CXCR4-CXCR7 involving cyclophilin A, CXCR7 ubiquitination and promotes platelet survival. FASEB J 2014, 28, 2864-2878, doi:10.1096/fj.14-249730.

38. Stellos, K.; Ruf, M.; Sopova, K.; Kilias, A.; Rahmann, A.; Stamatelopoulos, K.; Jorbenadze, R.; Geisler, T.; Gawaz, M.; Bigalke, B. Plasma levels of stromal cell-derived factor-1 in patients with coronary artery disease: effect of clinical presentation and cardiovascular risk factors. Atherosclerosis 2011, 219, 913-916, doi:10.1016/j.atherosclerosis.2011.09.022.

39. Alampour-Rajabi, S.; El Bounkari, O.; Rot, A.; Muller-Newen, G.; Bachelerie, F.; Gawaz, M.; Weber, C.; Schober, A.; Bernhagen, J. MIF interacts with CXCR7 to promote receptor internalization, ERK1/2 and ZAP-70 signaling, and lymphocyte chemotaxis. FASEB J 2015, 29, 4497-4511, doi:10.1096/fj.15-273904.

40. Chatterjee, M.; Borst, O.; Walker, B.; Fotinos, A.; Vogel, S.; Seizer, P.; Mack, A.; Alampour-Rajabi, S.; Rath, D.; Geisler, T., et al. Macrophage migration inhibitory factor limits activation-induced apoptosis of platelets via CXCR7-dependent Akt signaling. Circ Res 2014, 115, 939-949, doi:10.1161/CIRCRESAHA.115.305171.

41. Canals, M.; Scholten, D.J.; de Munnik, S.; Han, M.K.; Smit, M.J.; Leurs, R. Ubiquitination of CXCR7 controls receptor trafficking. PLoS One 2012, 7, e34192, doi:10.1371/journal.pone.0034192.

42. Schwartz, V.; Lue, H.; Kraemer, S.; Korbiel, J.; Krohn, R.; Ohl, K.; Bucala, R.; Weber, C.; Bernhagen, J. A functional heteromeric MIF receptor formed by CD74 and CXCR4. FEBS Lett 2009, 583, 2749-2757, doi:10.1016/j.febslet.2009.07.058.

43. Rath, D.; Chatterjee, M.; Bongartz, A.; Muller, K.; Droppa, M.; Stimpfle, F.; Borst, O.; Zuern, C.; Vogel, S.; Gawaz, M., et al. Platelet surface expression of SDF-1 is associated with clinical outcomes in the patients with cardiovascular disease. Platelets 2017, 28, 34-39, doi:10.1080/09537104.2016.1203399.

44. Muller, II; Muller, K.A.; Schonleber, H.; Karathanos, A.; Schneider, M.; Jorbenadze, R.; Bigalke, B.; Gawaz, M.; Geisler, T. Macrophage migration inhibitory factor is enhanced in acute coronary syndromes and is associated with the inflammatory response. PLoS One 2012, 7, e38376, doi:10.1371/journal.pone.0038376.

45. Koch, C.; Engele, J. Functions of the CXCL12 Receptor ACKR3/CXCR7-What Has Been Perceived and What Has Been Overlooked. Mol Pharmacol 2020, 98, 577-585, doi:10.1124/molpharm.120.000056.

46. Kawaguchi, N.; Zhang, T.T.; Nakanishi, T. Involvement of CXCR4 in Normal and Abnormal Development. Cells 2019, 8, doi:10.3390/cells8020185.

47. Janssens, R.; Struyf, S.; Proost, P. Pathological roles of the homeostatic chemokine CXCL12. Cytokine Growth Factor Rev 2018, 44, 51-68, doi:10.1016/j.cytogfr.2018.10.004.

48. Teixido, J.; Martinez-Moreno, M.; Diaz-Martinez, M.; Sevilla-Movilla, S. The good and bad faces of the CXCR4 chemokine receptor. Int J Biochem Cell Biol 2018, 95, 121-131, doi:10.1016/j.biocel.2017.12.018.

49. Riviere, C.; Subra, F.; Cohen-Solal, K.; Cordette-Lagarde, V.; Letestu, R.; Auclair, C.; Vainchenker, W.; Louache, F. Phenotypic and functional evidence for the expression of CXCR4 receptor during megakaryocytopoiesis. Blood 1999, 93, $1511-1523$

50. Wang, J.F.; Liu, Z.Y.; Groopman, J.E. The alpha-chemokine receptor CXCR4 is expressed on the megakaryocytic lineage from progenitor to platelets and modulates migration and adhesion. Blood 1998, 92, 756-764.

51. Kowalska, M.A.; Ratajczak, J.; Hoxie, J.; Brass, L.F.; Gewirtz, A.; Poncz, M.; Ratajczak, M.Z. Megakaryocyte precursors, megakaryocytes and platelets express the HIV co-receptor CXCR4 on their surface: determination of response to stromalderived factor-1 by megakaryocytes and platelets. Br J Haematol 1999, 104, 220-229, doi:10.1046/j.1365-2141.1999.01169.x. 
Secchiero, P.; Celeghini, C.; Cutroneo, G.; Di Baldassarre, A.; Rana, R.; Zauli, G. Differential effects of stromal derived factor1 alpha (SDF-1 alpha) on early and late stages of human megakaryocytic development. Anat Rec 2000, 260, 141-147, doi:10.1002/1097-0185(20001001)260:2<141::AID-AR40>3.0.CO;2-I.

53. Hamada, T.; Mohle, R.; Hesselgesser, J.; Hoxie, J.; Nachman, R.L.; Moore, M.A.; Rafii, S. Transendothelial migration of megakaryocytes in response to stromal cell-derived factor 1 (SDF-1) enhances platelet formation. J Exp Med 1998, 188, 539548, doi:10.1084/jem.188.3.539.

54. Wagner, N.; Mott, K.; Upcin, B.; Stegner, D.; Schulze, H.; Ergun, S. CXCL12-Abundant Reticular (CAR) Cells Direct Megakaryocyte Protrusions across the Bone Marrow Sinusoid Wall. Cells 2021, 10, doi:10.3390/cells10040722.

55. Kraemer, B.F.; Borst, O.; Gehring, E.M.; Schoenberger, T.; Urban, B.; Ninci, E.; Seizer, P.; Schmidt, C.; Bigalke, B.; Koch, M., et al. PI3 kinase-dependent stimulation of platelet migration by stromal cell-derived factor 1 (SDF-1). J Mol Med (Berl) 2010, 88, 1277-1288, doi:10.1007/s00109-010-0680-8.

56. Kraemer, B.F.; Schmidt, C.; Urban, B.; Bigalke, B.; Schwanitz, L.; Koch, M.; Seizer, P.; Schaller, M.; Gawaz, M.; Lindemann, S. High shear flow induces migration of adherent human platelets. Platelets 2011, 22, 415-421, doi:10.3109/09537104.2011.556277.

57. Abi-Younes, S.; Sauty, A.; Mach, F.; Sukhova, G.K.; Libby, P.; Luster, A.D. The stromal cell-derived factor-1 chemokine is a potent platelet agonist highly expressed in atherosclerotic plaques. Circ Res 2000, 86, 131-138, doi:10.1161/01.res.86.2.131.

58. Gear, A.R.; Suttitanamongkol, S.; Viisoreanu, D.; Polanowska-Grabowska, R.K.; Raha, S.; Camerini, D. Adenosine diphosphate strongly potentiates the ability of the chemokines MDC, TARC, and SDF-1 to stimulate platelet function. Blood 2001, 97, 937-945, doi:10.1182/blood.v97.4.937.

59. Walsh, T.G.; Harper, M.T.; Poole, A.W. SDF-1alpha is a novel autocrine activator of platelets operating through its receptor CXCR4. Cell Signal 2015, 27, 37-46, doi:10.1016/j.cellsig.2014.09.021.

60. Gear, A.R.; Camerini, D. Platelet chemokines and chemokine receptors: linking hemostasis, inflammation, and host defense. Microcirculation 2003, 10, 335-350, doi:10.1038/sj.mn.7800198.

61. Kowalska, M.A.; Ratajczak, M.Z.; Majka, M.; Jin, J.; Kunapuli, S.; Brass, L.; Poncz, M. Stromal cell-derived factor-1 and macrophage-derived chemokine: 2 chemokines that activate platelets. Blood 2000, 96, 50-57.

Salim, J.P.; Goette, N.P.; Lev, P.R.; Chazarreta, C.D.; Heller, P.G.; Alvarez, C.; Molinas, F.C.; Marta, R.F. Dysregulation of stromal derived factor 1/CXCR4 axis in the megakaryocytic lineage in essential thrombocythemia. Br J Haematol 2009, 144, 69-77, doi:10.1111/j.1365-2141.2008.07428.x.

63. Chatterjee, M.; Rath, D.; Schlotterbeck, J.; Rheinlaender, J.; Walker-Allgaier, B.; Alnaggar, N.; Zdanyte, M.; Muller, I.; Borst, O.; Geisler, T., et al. Regulation of oxidized platelet lipidome: implications for coronary artery disease. Eur Heart J 2017, 38 , 1993-2005, doi:10.1093/eurheartj/ehx146.

64. Ohtsuka, H.; Iguchi, T.; Hayashi, M.; Kaneda, M.; Iida, K.; Shimonaka, M.; Hara, T.; Arai, M.; Koike, Y.; Yamamoto, N., et al. SDF-1alpha/CXCR4 Signaling in Lipid Rafts Induces Platelet Aggregation via PI3 Kinase-Dependent Akt Phosphorylation. PLoS One 2017, 12, e0169609, doi:10.1371/journal.pone.0169609.

65. Stellos, K.; Sauter, R.; Fahrleitner, M.; Grimm, J.; Stakos, D.; Emschermann, F.; Panagiota, V.; Gnerlich, S.; Perk, A.; Schonberger, T., et al. Binding of oxidized low-density lipoprotein on circulating platelets is increased in patients with acute coronary syndromes and induces platelet adhesion to vascular wall in vivo--brief report. Arterioscler Thromb Vasc Biol 2012, 32, 2017-2020, doi:10.1161/ATVBAHA.111.244707.

66. Wang, J.; Tannous, B.A.; Poznansky, M.C.; Chen, H. CXCR4 antagonist AMD3100 (plerixafor): From an impurity to a therapeutic agent. Pharmacol Res 2020, 159, 105010, doi:10.1016/j.phrs.2020.105010.

67. Bobkov, V.; Arimont, M.; Zarca, A.; De Groof, T.W.M.; van der Woning, B.; de Haard, H.; Smit, M.J. Antibodies Targeting Chemokine Receptors CXCR4 and ACKR3. Mol Pharmacol 2019, 96, 753-764, doi:10.1124/mol.119.116954. 
68. Mujic-Delic, A.; de Wit, R.H.; Verkaar, F.; Smit, M.J. GPCR-targeting nanobodies: attractive research tools, diagnostics, and therapeutics. Trends Pharmacol Sci 2014, 35, 247-255, doi:10.1016/j.tips.2014.03.003.

69. Kaplan, J.E.; Saba, T.M. Platelet removal from the circulation by the liver and spleen. Am J Physiol 1978, 235, H314-320, doi:10.1152/ajpheart.1978.235.3.H314.

70. Montenont, E.; Rondina, M.T.; Campbell, R.A. Altered functions of platelets during aging. Curr Opin Hematol 2019, 26, 336342, doi:10.1097/MOH.0000000000000526.

71. McArthur, K.; Chappaz, S.; Kile, B.T. Apoptosis in megakaryocytes and platelets: the life and death of a lineage. Blood 2018, 131, 605-610, doi:10.1182/blood-2017-11-742684.

Davizon-Castillo, P.; Rowley, J.W.; Rondina, M.T. Megakaryocyte and Platelet Transcriptomics for Discoveries in Human Health and Disease. Arterioscler Thromb Vasc Biol 2020, 40, 1432-1440, doi:10.1161/ATVBAHA.119.313280.

73. Handtke, S.; Steil, L.; Greinacher, A.; Thiele, T. Toward the Relevance of Platelet Subpopulations for Transfusion Medicine. Front Med (Lausanne) 2018, 5, 17, doi:10.3389/fmed.2018.00017.

74. Wirtz, T.H.; Tillmann, S.; Strussmann, T.; Kraemer, S.; Heemskerk, J.W.; Grottke, O.; Gawaz, M.; von Hundelshausen, P.; Bernhagen, J. Platelet-derived MIF: a novel platelet chemokine with distinct recruitment properties. Atherosclerosis 2015, 239, 1-10, doi:10.1016/j.atherosclerosis.2014.12.039.

75. Strussmann, T.; Tillmann, S.; Wirtz, T.; Bucala, R.; von Hundelshausen, P.; Bernhagen, J. Platelets are a previously unrecognised source of MIF. Thromb Haemost 2013, 110, 1004-1013, doi:10.1160/TH13-01-0049.

76. Cebo, M.; Dittrich, K.; Fu, X.; Manke, M.C.; Emschermann, F.; Rheinlaender, J.; von Eysmondt, H.; Ferreiros, N.; SudmannInnerhofer, J.; Witte, A., et al. Platelet ACKR3/CXCR7 Favors Anti-Platelet Lipids over an Atherothrombotic Lipidome and Regulates Thrombo-inflammation. Blood 2021, 10.1182/blood.2021013097, doi:10.1182/blood.2021013097.

77. Perdomo, J.; Leung, H.H.L.; Ahmadi, Z.; Yan, F.; Chong, J.J.H.; Passam, F.H.; Chong, B.H. Neutrophil activation and NETosis are the major drivers of thrombosis in heparin-induced thrombocytopenia. Nat Commun 2019, 10, 1322, doi:10.1038/s41467-019-09160-7.

78. Elia, E.; Montecucco, F.; Portincasa, P.; Sahebkar, A.; Mollazadeh, H.; Carbone, F. Update on pathological platelet activation in coronary thrombosis. J Cell Physiol 2019, 234, 2121-2133, doi:10.1002/jcp.27575.

79. Middleton, E.A.; He, X.Y.; Denorme, F.; Campbell, R.A.; Ng, D.; Salvatore, S.P.; Mostyka, M.; Baxter-Stoltzfus, A.; Borczuk, A.C.; Loda, M., et al. Neutrophil extracellular traps contribute to immunothrombosis in COVID-19 acute respiratory distress syndrome. Blood 2020, 136, 1169-1179, doi:10.1182/blood.2020007008.

80. Oikonomou, E.; Leopoulou, M.; Theofilis, P.; Antonopoulos, A.S.; Siasos, G.; Latsios, G.; Mystakidi, V.C.; Antoniades, C.; Tousoulis, D. A link between inflammation and thrombosis in atherosclerotic cardiovascular diseases: Clinical and therapeutic implications. Atherosclerosis 2020, 309, 16-26, doi:10.1016/j.atherosclerosis.2020.07.027.

81. d'Alessandro, E.; Becker, C.; Bergmeier, W.; Bode, C.; Bourne, J.H.; Brown, H.; Buller, H.R.; Ten Cate-Hoek, A.J.; Ten Cate, V.; van Cauteren, Y.J.M., et al. Thrombo-Inflammation in Cardiovascular Disease: An Expert Consensus Document from the Third Maastricht Consensus Conference on Thrombosis. Thromb Haemost 2020, 120, 538-564, doi:10.1055/s-0040-1708035. Zaid, Y.; Puhm, F.; Allaeys, I.; Naya, A.; Oudghiri, M.; Khalki, L.; Limami, Y.; Zaid, N.; Sadki, K.; Ben El Haj, R., et al. Platelets Can Associate with SARS-Cov-2 RNA and Are Hyperactivated in COVID-19. Circ Res 2020, 10.1161/CIRCRESAHA.120.317703, doi:10.1161/CIRCRESAHA.120.317703.

83. Guo, L.; Rondina, M.T. The Era of Thromboinflammation: Platelets Are Dynamic Sensors and Effector Cells During Infectious Diseases. Front Immunol 2019, 10, 2204, doi:10.3389/fimmu.2019.02204.

84. Weber, C.; Badimon, L.; Mach, F.; van der Vorst, E.P.C. Therapeutic strategies for atherosclerosis and atherothrombosis: Past, present and future. Thromb Haemost 2017, 117, 1258-1264, doi:10.1160/TH16-10-0814. 
85. McFadyen, J.D.; Stevens, H.; Peter, K. The Emerging Threat of (Micro)Thrombosis in COVID-19 and Its Therapeutic Implications. Circ Res 2020, 127, 571-587, doi:10.1161/CIRCRESAHA.120.317447.

86. Althaus, K.; Marini, I.; Zlamal, J.; Pelzl, L.; Singh, A.; Haberle, H.; Mehrlander, M.; Hammer, S.; Schulze, H.; Bitzer, M., et al. Antibody-induced procoagulant platelets in severe COVID-19 infection. Blood 2021, 137, 1061-1071, doi:10.1182/blood.2020008762.

87. Manne, B.K.; Denorme, F.; Middleton, E.A.; Portier, I.; Rowley, J.W.; Stubben, C.; Petrey, A.C.; Tolley, N.D.; Guo, L.; Cody, M., et al. Platelet gene expression and function in patients with COVID-19. Blood 2020, 136, 1317-1329, doi:10.1182/blood.2020007214.

88. Wang, J.; Zhang, S.; Jin, Y.; Qin, G.; Yu, L.; Zhang, J. Elevated levels of platelet-monocyte aggregates and related circulating biomarkers in patients with acute coronary syndrome. Int J Cardiol 2007, 115, 361-365, doi:10.1016/j.ijcard.2006.03.019.

89. Salah, H.M.; Mehta, J.L. Meta-Analysis of the Effect of Aspirin on Mortality in COVID-19. Am J Cardiol 2021, 142, 158-159, doi:10.1016/j.amjcard.2020.12.073.

90. Koenen, J.; Bachelerie, F.; Balabanian, K.; Schlecht-Louf, G.; Gallego, C. Atypical Chemokine Receptor 3 (ACKR3): A Comprehensive Overview of its Expression and Potential Roles in the Immune System. Mol Pharmacol 2019, 96, 809-818, doi:10.1124/mol.118.115329.

91. Ngamsri, K.C.; Muller, A.; Bosmuller, H.; Gamper-Tsigaras, J.; Reutershan, J.; Konrad, F.M. The Pivotal Role of CXCR7 in Stabilization of the Pulmonary Epithelial Barrier in Acute Pulmonary Inflammation. J Immunol 2017, 198, 2403-2413, doi:10.4049/jimmunol.1601682.

92. Pouzol, L.; Sassi, A.; Baumlin, N.; Tunis, M.; Strasser, D.S.; Lehembre, F.; Martinic, M.M. CXCR7 Antagonism Reduces Acute Lung Injury Pathogenesis. Front Pharmacol 2021, 12, 748740, doi:10.3389/fphar.2021.748740.

93. Greinacher, A.; Thiele, T.; Warkentin, T.E.; Weisser, K.; Kyrle, P.A.; Eichinger, S. Thrombotic Thrombocytopenia after ChAdOx1 nCov-19 Vaccination. N Engl J Med 2021, 10.1056/NEJMoa2104840, doi:10.1056/NEJMoa2104840.

94. Yeung, J.; Tourdot, B.E.; Adili, R.; Green, A.R.; Freedman, C.J.; Fernandez-Perez, P.; Yu, J.; Holman, T.R.; Holinstat, M. 12(S)HETrE, a 12-Lipoxygenase Oxylipin of Dihomo-gamma-Linolenic Acid, Inhibits Thrombosis via Galphas Signaling in Platelets. Arterioscler Thromb Vasc Biol 2016, 36, 2068-2077, doi:10.1161/ATVBAHA.116.308050.

95. Tourdot, B.E.; Ahmed, I.; Holinstat, M. The emerging role of oxylipins in thrombosis and diabetes. Front Pharmacol 2014, 4, 176, doi:10.3389/fphar.2013.00176.

96. Harm, T.; Bild, A.; Dittrich, K.; Goldschmied, A.; Nestele, J.; Chatterjee, M.; Fu, X.; Kolb, K.; Castor, T.; Borst, O., et al. Acute coronary syndrome is associated with a substantial change in the platelet lipidome. Cardiovasc Res 2021, 10.1093/cvr/cvab238, doi:10.1093/cvr/cvab238.

97. Diehl, P.; Nienaber, F.; Zaldivia, M.T.K.; Stamm, J.; Siegel, P.M.; Mellett, N.A.; Wessinger, M.; Wang, X.; McFadyen, J.D.; Bassler, N., et al. Lysophosphatidylcholine is a Major Component of Platelet Microvesicles Promoting Platelet Activation and Reporting Atherosclerotic Plaque Instability. Thromb Haemost 2019, 119, 1295-1310, doi:10.1055/s-0039-1683409.

98. Tourdot, B.E.; Adili, R.; Isingizwe, Z.R.; Ebrahem, M.; Freedman, J.C.; Holman, T.R.; Holinstat, M. 12-HETrE inhibits platelet reactivity and thrombosis in part through the prostacyclin receptor. Blood Adv 2017, 1, 1124-1131, doi:10.1182/bloodadvances.2017006155.

99. Yeung, J.; Tourdot, B.E.; Fernandez-Perez, P.; Vesci, J.; Ren, J.; Smyrniotis, C.J.; Luci, D.K.; Jadhav, A.; Simeonov, A.; Maloney, D.J., et al. Platelet 12-LOX is essential for FcgammaRIla-mediated platelet activation. Blood 2014, 124, 2271-2279, doi:10.1182/blood-2014-05-575878.

100. Burkard, P.; Vogtle, T.; Nieswandt, B. Platelets in Thrombo-Inflammation: Concepts, Mechanisms, and Therapeutic Strategies for Ischemic Stroke. Hamostaseologie 2020, 40, 153-164, doi:10.1055/a-1151-9519. 
101. Stoll, G.; Nieswandt, B. Thrombo-inflammation in acute ischaemic stroke - implications for treatment. Nat Rev Neurol 2019, 15, 473-481, doi:10.1038/s41582-019-0221-1.

102. Chatterjee, M.; Ehrenberg, A.; Toska, L.M.; Metz, L.M.; Klier, M.; Krueger, I.; Reusswig, F.; Elvers, M. Molecular Drivers of Platelet Activation: Unraveling Novel Targets for Anti-Thrombotic and Anti-Thrombo-Inflammatory Therapy. Int J Mol Sci 2020, 21, doi:10.3390/ijms21217906.

103. Li, X.; Zhu, M.; Penfold, M.E.; Koenen, R.R.; Thiemann, A.; Heyll, K.; Akhtar, S.; Koyadan, S.; Wu, Z.; Gremse, F., et al. Activation of CXCR7 limits atherosclerosis and improves hyperlipidemia by increasing cholesterol uptake in adipose tissue. Circulation 2014, 129, 1244-1253, doi:10.1161/CIRCULATIONAHA.113.006840.

104. Cao, Z.; Lis, R.; Ginsberg, M.; Chavez, D.; Shido, K.; Rabbany, S.Y.; Fong, G.H.; Sakmar, T.P.; Rafii, S.; Ding, B.S. Targeting of the pulmonary capillary vascular niche promotes lung alveolar repair and ameliorates fibrosis. Nat Med 2016, 22, 154-162, doi:10.1038/nm.4035.

105. Ding, B.S.; Cao, Z.; Lis, R.; Nolan, D.J.; Guo, P.; Simons, M.; Penfold, M.E.; Shido, K.; Rabbany, S.Y.; Rafii, S. Divergent angiocrine signals from vascular niche balance liver regeneration and fibrosis. Nature 2014, 505, 97-102, doi:10.1038/nature12681.

106. Xu, D.; Li, R.; Wu, J.; Jiang, L.; Zhong, H.A. Drug Design Targeting the CXCR4/CXCR7/CXCL12 Pathway. Curr Top Med Chem 2016, 16, 1441-1451, doi:10.2174/1568026615666150915120218.

107. Wijtmans, M.; Maussang, D.; Sirci, F.; Scholten, D.J.; Canals, M.; Mujic-Delic, A.; Chong, M.; Chatalic, K.L.; Custers, H.; Janssen, E., et al. Synthesis, modeling and functional activity of substituted styrene-amides as small-molecule CXCR7 agonists. Eur J Med Chem 2012, 51, 184-192, doi:10.1016/j.ejmech.2012.02.041.

108. Wang, C.; Chen, W.; Shen, J. CXCR7 Targeting and Its Major Disease Relevance. Front Pharmacol 2018, 9, 641, doi:10.3389/fphar.2018.00641.

109. Gravel, S.; Malouf, C.; Boulais, P.E.; Berchiche, Y.A.; Oishi, S.; Fujii, N.; Leduc, R.; Sinnett, D.; Heveker, N. The peptidomimetic CXCR4 antagonist TC14012 recruits beta-arrestin to CXCR7: roles of receptor domains. J Biol Chem 2010, 285, 37939-37943, doi:10.1074/jbc.C110.147470.

110. Kalatskaya, I.; Berchiche, Y.A.; Gravel, S.; Limberg, B.J.; Rosenbaum, J.S.; Heveker, N. AMD3100 is a CXCR7 ligand with allosteric agonist properties. Mol Pharmacol 2009, 75, 1240-1247, doi:10.1124/mol.108.053389.

111. Ma, W.; Liu, Y.; Ellison, N.; Shen, J. Induction of C-X-C chemokine receptor type 7 (CXCR7) switches stromal cell-derived factor-1 (SDF-1) signaling and phagocytic activity in macrophages linked to atherosclerosis. J Biol Chem 2013, 288, 1548115494, doi:10.1074/jbc.M112.445510.

112. Ma, W.; Liu, Y.; Wang, C.; Zhang, L.; Crocker, L.; Shen, J. Atorvastatin inhibits CXCR7 induction to reduce macrophage migration. Biochem Pharmacol 2014, 89, 99-108, doi:10.1016/j.bcp.2014.02.014.

113. Jiang, C.; Li, R.; Ma, X.; Hu, H.; Guo, J.; Zhao, J. AMD3100 and SDF1 regulate cellular functions of endothelial progenitor cells and accelerate endothelial regeneration in a rat carotid artery injury model. Mol Med Rep 2020, 22, 3201-3212, doi:10.3892/mmr.2020.11432.

114. Saaber, F.; Schutz, D.; Miess, E.; Abe, P.; Desikan, S.; Ashok Kumar, P.; Balk, S.; Huang, K.; Beaulieu, J.M.; Schulz, S., et al. ACKR3 Regulation of Neuronal Migration Requires ACKR3 Phosphorylation, but Not beta-Arrestin. Cell Rep 2019, 26, 14731488 e1479, doi:10.1016/j.celrep.2019.01.049.

115. Walter, H.L.; van der Maten, G.; Antunes, A.R.; Wieloch, T.; Ruscher, K. Treatment with AMD3100 attenuates the microglial response and improves outcome after experimental stroke. J Neuroinflammation 2015, 12, 24, doi:10.1186/s12974-014-0232-1.

116. Siegel-Axel, D.; Daub, K.; Seizer, P.; Lindemann, S.; Gawaz, M. Platelet lipoprotein interplay: trigger of foam cell formation and driver of atherosclerosis. Cardiovasc Res 2008, 78, 8-17, doi:10.1093/cvr/cvn015. 
117. Hu, X.; Dai, S.; Wu, W.J.; Tan, W.; Zhu, X.; Mu, J.; Guo, Y.; Bolli, R.; Rokosh, G. Stromal cell derived factor-1 alpha confers protection against myocardial ischemia/reperfusion injury: role of the cardiac stromal cell derived factor-1 alpha CXCR4 axis. Circulation 2007, 116, 654-663, doi:10.1161/CIRCULATIONAHA.106.672451.

118. Jujo, K.; Hamada, H.; Iwakura, A.; Thorne, T.; Sekiguchi, H.; Clarke, T.; Ito, A.; Misener, S.; Tanaka, T.; Klyachko, E., et al. CXCR4 blockade augments bone marrow progenitor cell recruitment to the neovasculature and reduces mortality after myocardial infarction. Proc Natl Acad Sci U S A 2010, 107, 11008-11013, doi:10.1073/pnas.0914248107.

119. Thackeray, J.T.; Derlin, T.; Haghikia, A.; Napp, L.C.; Wang, Y.; Ross, T.L.; Schafer, A.; Tillmanns, J.; Wester, H.J.; Wollert, K.C., et al. Molecular Imaging of the Chemokine Receptor CXCR4 After Acute Myocardial Infarction. JACC Cardiovasc Imaging 2015, 8, 1417-1426, doi:10.1016/j.jcmg.2015.09.008.

120. Wang, J.; Gareri, C.; Rockman, H.A. G-Protein-Coupled Receptors in Heart Disease. Circ Res 2018, 123, 716-735, doi:10.1161/CIRCRESAHA.118.311403.

121. Wisler, J.W.; DeWire, S.M.; Whalen, E.J.; Violin, J.D.; Drake, M.T.; Ahn, S.; Shenoy, S.K.; Lefkowitz, R.J. A unique mechanism of beta-blocker action: carvedilol stimulates beta-arrestin signaling. Proc Natl Acad Sci U S A 2007, 104, 16657-16662, doi:10.1073/pnas.0707936104.

122. Ryba, D.M.; Li, J.; Cowan, C.L.; Russell, B.; Wolska, B.M.; Solaro, R.J. Long-Term Biased beta-Arrestin Signaling Improves Cardiac Structure and Function in Dilated Cardiomyopathy. Circulation 2017, 135, 1056-1070, doi:10.1161/CIRCULATIONAHA.116.024482.

123. Escot, S.; Blavet, C.; Hartle, S.; Duband, J.L.; Fournier-Thibault, C. Misregulation of SDF1-CXCR4 signaling impairs early cardiac neural crest cell migration leading to conotruncal defects. Circ Res 2013, 113, 505-516, doi:10.1161/CIRCRESAHA.113.301333.

124. LaRocca, T.J.; Altman, P.; Jarrah, A.A.; Gordon, R.; Wang, E.; Hadri, L.; Burke, M.W.; Haddad, G.E.; Hajjar, R.J.; Tarzami, S.T. CXCR4 Cardiac Specific Knockout Mice Develop a Progressive Cardiomyopathy. Int J Mol Sci 2019, 20, doi:10.3390/ijms20092267.

125. Agarwal, U.; Ghalayini, W.; Dong, F.; Weber, K.; Zou, Y.R.; Rabbany, S.Y.; Rafii, S.; Penn, M.S. Role of cardiac myocyte CXCR4 expression in development and left ventricular remodeling after acute myocardial infarction. Circ Res 2010, 107, 667676, doi:10.1161/CIRCRESAHA.110.223289.

126. Sierro, F.; Biben, C.; Martinez-Munoz, L.; Mellado, M.; Ransohoff, R.M.; Li, M.; Woehl, B.; Leung, H.; Groom, J.; Batten, M., et al. Disrupted cardiac development but normal hematopoiesis in mice deficient in the second CXCL12/SDF-1 receptor, CXCR7. Proc Natl Acad Sci U S A 2007, 104, 14759-14764, doi:10.1073/pnas.0702229104.

127. Yu, S.; Crawford, D.; Tsuchihashi, T.; Behrens, T.W.; Srivastava, D. The chemokine receptor CXCR7 functions to regulate cardiac valve remodeling. Dev Dyn 2011, 240, 384-393, doi:10.1002/dvdy.22549.

128. Betterman, K.L.; Harvey, N.L. Decoys and cardiovascular development: CXCR7 and regulation of adrenomedullin signaling. Dev Cell 2014, 30, 490-491, doi:10.1016/j.devcel.2014.08.021.

129. Klein, K.R.; Karpinich, N.O.; Espenschied, S.T.; Willcockson, H.H.; Dunworth, W.P.; Hoopes, S.L.; Kushner, E.J.; Bautch, V.L.; Caron, K.M. Decoy receptor CXCR7 modulates adrenomedullin-mediated cardiac and lymphatic vascular development. Dev Cell 2014, 30, 528-540, doi:10.1016/j.devcel.2014.07.012.

130. Gerrits, H.; van Ingen Schenau, D.S.; Bakker, N.E.; van Disseldorp, A.J.; Strik, A.; Hermens, L.S.; Koenen, T.B.; KrajncFranken, M.A.; Gossen, J.A. Early postnatal lethality and cardiovascular defects in CXCR7-deficient mice. Genesis 2008, 46, 235-245, doi:10.1002/dvg.20387.

131. Ceholski, D.K.; Turnbull, I.C.; Pothula, V.; Lecce, L.; Jarrah, A.A.; Kho, C.; Lee, A.; Hadri, L.; Costa, K.D.; Hajjar, R.J., et al. CXCR4 and CXCR7 play distinct roles in cardiac lineage specification and pharmacologic beta-adrenergic response. Stem Cell Res 2017, 23, 77-86, doi:10.1016/j.scr.2017.06.015. 
132. Ghadge, S.K.; Messner, M.; Seiringer, H.; Maurer, T.; Staggl, S.; Zeller, T.; Muller, C.; Bornigen, D.; Weninger, W.J.; Geyer, S.H., et al. Smooth Muscle Specific Ablation of CXCL12 in Mice Downregulates CXCR7 Associated with Defective Coronary Arteries and Cardiac Hypertrophy. Int J Mol Sci 2021, 22, doi:10.3390/ijms22115908.

133. Hess, A.; Derlin, T.; Koenig, T.; Diekmann, J.; Wittneben, A.; Wang, Y.; Wester, H.J.; Ross, T.L.; Wollert, K.C.; Bauersachs, J., et al. Molecular imaging-guided repair after acute myocardial infarction by targeting the chemokine receptor CXCR4. Eur Heart J 2020, 41, 3564-3575, doi:10.1093/eurheartj/ehaa598.

134. Proulx, C.; El-Helou, V.; Gosselin, H.; Clement, R.; Gillis, M.A.; Villeneuve, L.; Calderone, A. Antagonism of stromal cellderived factor-1alpha reduces infarct size and improves ventricular function after myocardial infarction. Pflugers Arch 2007, 455, 241-250, doi:10.1007/s00424-007-0284-5.

135. Jujo, K.; Ii, M.; Sekiguchi, H.; Klyachko, E.; Misener, S.; Tanaka, T.; Tongers, J.; Roncalli, J.; Renault, M.A.; Thorne, T., et al. CXC-chemokine receptor 4 antagonist AMD3100 promotes cardiac functional recovery after ischemia/reperfusion injury via endothelial nitric oxide synthase-dependent mechanism. Circulation 2013, 127, 63-73, doi:10.1161/CIRCULATIONAHA.112.099242.

136. Roncalli, J.; Renault, M.A.; Tongers, J.; Misener, S.; Thorne, T.; Kamide, C.; Jujo, K.; Tanaka, T.; Ii, M.; Klyachko, E., et al. Sonic hedgehog-induced functional recovery after myocardial infarction is enhanced by AMD3100-mediated progenitorcell mobilization. J Am Coll Cardiol 2011, 57, 2444-2452, doi:10.1016/j.jacc.2010.11.069.

137. Lohse, M.J.; Engelhardt, S.; Eschenhagen, T. What is the role of beta-adrenergic signaling in heart failure? Circ Res 2003, 93, 896-906, doi:10.1161/01.RES.0000102042.83024.CA.

138. Noor, N.; Patel, C.B.; Rockman, H.A. Beta-arrestin: a signaling molecule and potential therapeutic target for heart failure. J Mol Cell Cardiol 2011, 51, 534-541, doi:10.1016/j.yjmcc.2010.11.005.

139. Davidson, S.M.; Andreadou, I.; Barile, L.; Birnbaum, Y.; Cabrera-Fuentes, H.A.; Cohen, M.V.; Downey, J.M.; Girao, H.; Pagliaro, P.; Penna, C., et al. Circulating blood cells and extracellular vesicles in acute cardioprotection. Cardiovasc Res 2019, 115, 1156-1166, doi:10.1093/cvr/cvy314.

140. Zuurbier, C.J.; Abbate, A.; Cabrera-Fuentes, H.A.; Cohen, M.V.; Collino, M.; De Kleijn, D.P.V.; Downey, J.M.; Pagliaro, P.; Preissner, K.T.; Takahashi, M., et al. Innate immunity as a target for acute cardioprotection. Cardiovasc Res 2019, 115, 11311142, doi:10.1093/cvr/cvy304.

141. Hausenloy, D.J.; Chilian, W.; Crea, F.; Davidson, S.M.; Ferdinandy, P.; Garcia-Dorado, D.; van Royen, N.; Schulz, R.; Heusch, G. The coronary circulation in acute myocardial ischaemia/reperfusion injury: a target for cardioprotection. Cardiovasc Res 2019, 115, 1143-1155, doi:10.1093/cvr/cry286.

142. Andreadou, I.; Cabrera-Fuentes, H.A.; Devaux, Y.; Frangogiannis, N.G.; Frantz, S.; Guzik, T.; Liehn, E.A.; Gomes, C.P.C.; Schulz, R.; Hausenloy, D.J. Immune cells as targets for cardioprotection: new players and novel therapeutic opportunities. Cardiovasc Res 2019, 115, 1117-1130, doi:10.1093/cvr/cvz050.

143. Hohmann, J.D.; Wang, X.; Krajewski, S.; Selan, C.; Haller, C.A.; Straub, A.; Chaikof, E.L.; Nandurkar, H.H.; Hagemeyer, C.E.; Peter, K. Delayed targeting of CD39 to activated platelet GPIIb/IIIa via a single-chain antibody: breaking the link between antithrombotic potency and bleeding? Blood 2013, 121, 3067-3075, doi:10.1182/blood-2012-08-449694.

144. Ziegler, M.; Haigh, K.; Nguyen, T.; Wang, X.; Lim, B.; Yap, M.L.; Eddy, E.M.; Haigh, J.J.; Peter, K. The pulmonary microvasculature entraps induced vascular progenitor cells (iVPCs) systemically delivered after cardiac ischemiareperfusion injury: Indication for preservation of heart function via paracrine effects beyond engraftment. Microcirculation 2019, 26, e12493, doi:10.1111/micc.12493.

145. Ziegler, M.; Alt, K.; Paterson, B.M.; Kanellakis, P.; Bobik, A.; Donnelly, P.S.; Hagemeyer, C.E.; Peter, K. Highly Sensitive Detection of Minimal Cardiac Ischemia using Positron Emission Tomography Imaging of Activated Platelets. Sci Rep 2016, 6, 38161, doi:10.1038/srep38161. 
146. Wang, X.; Peter, K. Molecular Imaging of Atherothrombotic Diseases: Seeing Is Believing. Arterioscler Thromb Vasc Biol 2017, 37, 1029-1040, doi:10.1161/ATVBAHA.116.306483.

147. Keane, C.; Tilley, D.; Cunningham, A.; Smolenski, A.; Kadioglu, A.; Cox, D.; Jenkinson, H.F.; Kerrigan, S.W. Invasive Streptococcus pneumoniae trigger platelet activation via Toll-like receptor 2. J Thromb Haemost 2010, 8, 2757-2765, doi:10.1111/j.1538-7836.2010.04093.x.

148. de Stoppelaar, S.F.; Claushuis, T.A.; Schaap, M.C.; Hou, B.; van der Poll, T.; Nieuwland, R.; van 't Veer, C. Toll-Like Receptor Signalling Is Not Involved in Platelet Response to Streptococcus pneumoniae In Vitro or In Vivo. PLoS One 2016, 11, e0156977, doi:10.1371/journal.pone.0156977.

149. Amison, R.T.; O'Shaughnessy, B.G.; Arnold, S.; Cleary, S.J.; Nandi, M.; Pitchford, S.C.; Bragonzi, A.; Page, C.P. Platelet Depletion Impairs Host Defense to Pulmonary Infection with Pseudomonas aeruginosa in Mice. Am J Respir Cell Mol Biol 2018, 58, 331-340, doi:10.1165/rcmb.2017-0083OC.

150. Boilard, E.; Pare, G.; Rousseau, M.; Cloutier, N.; Dubuc, I.; Levesque, T.; Borgeat, P.; Flamand, L. Influenza virus H1N1 activates platelets through FcgammaRIIA signaling and thrombin generation. Blood 2014, 123, 2854-2863, doi:10.1182/blood2013-07-515536.

151. Hottz, E.D.; Bozza, F.A.; Bozza, P.T. Platelets in Immune Response to Virus and Immunopathology of Viral Infections. Front Med (Lausanne) 2018, 5, 121, doi:10.3389/fmed.2018.00121.

152. Pitchford, S.; Cleary, S.; Arkless, K.; Amison, R. Pharmacological strategies for targeting platelet activation in asthma. Curr Opin Pharmacol 2019, 46, 55-64, doi:10.1016/j.coph.2019.03.012.

153. Takeda, T.; Morita, H.; Saito, H.; Matsumoto, K.; Matsuda, A. Recent advances in understanding the roles of blood platelets in the pathogenesis of allergic inflammation and bronchial asthma. Allergol Int 2018, 67, 326-333, doi:10.1016/j.alit.2017.11.008.

154. Mallah, H.; Ball, S.; Sekhon, J.; Parmar, K.; Nugent, K. Platelets in chronic obstructive pulmonary disease: An update on pathophysiology and implications for antiplatelet therapy. Respir Med 2020, 171, 106098, doi:10.1016/j.rmed.2020.106098.

155. Middleton, E.A.; Rondina, M.T.; Schwertz, H.; Zimmerman, G.A. Amicus or Adversary Revisited: Platelets in Acute Lung Injury and Acute Respiratory Distress Syndrome. Am J Respir Cell Mol Biol 2018, 59, 18-35, doi:10.1165/rcmb.2017-0420TR.

156. Chebbo, M.; Duez, C.; Alessi, M.C.; Chanez, P.; Gras, D. Platelets: a potential role in chronic respiratory diseases? Eur Respir Rev 2021, 30, doi:10.1183/16000617.0062-2021.

157. Kornerup, K.N.; Page, C.P. The role of platelets in the pathophysiology of asthma. Platelets 2007, 18, 319-328, doi:10.1080/09537100701230436.

158. Laidlaw, T.M.; Kidder, M.S.; Bhattacharyya, N.; Xing, W.; Shen, S.; Milne, G.L.; Castells, M.C.; Chhay, H.; Boyce, J.A. Cysteinyl leukotriene overproduction in aspirin-exacerbated respiratory disease is driven by platelet-adherent leukocytes. Blood 2012, 119, 3790-3798, doi:10.1182/blood-2011-10-384826.

159. Zhan, T.; Wei, T.; Dong, L.; Wang, Q.; Wu, Z.; Yan, Q.; Zhang, W.; Lu, Y.; Wu, M. Cangrelor alleviates bleomycin-induced pulmonary fibrosis by inhibiting platelet activation in mice. Mol Immunol 2020, 120, 83-92, doi:10.1016/j.molimm.2020.01.017.

160. Diehl, A.M. Neighborhood watch orchestrates liver regeneration. Nat Med 2012, 18, 497-499, doi:10.1038/nm.2719.

161. Caligiuri, A.; Gentilini, A.; Pastore, M.; Gitto, S.; Marra, F. Cellular and Molecular Mechanisms Underlying Liver Fibrosis Regression. Cells 2021, 10, doi:10.3390/cells10102759.

162. Cordero-Espinoza, L.; Huch, M. The balancing act of the liver: tissue regeneration versus fibrosis. J Clin Invest 2018, 128, 8596, doi:10.1172/JCI93562.

163. Khurana, A.; Sayed, N.; Allawadhi, P.; Weiskirchen, R. It's all about the spaces between cells: role of extracellular matrix in liver fibrosis. Ann Transl Med 2021, 9, 728, doi:10.21037/atm-20-2948. 
164. DeLeve, L.D.; Wang, X.; Wang, L. VEGF-sdf1 recruitment of CXCR7+ bone marrow progenitors of liver sinusoidal endothelial cells promotes rat liver regeneration. Am J Physiol Gastrointest Liver Physiol 2016, 310, G739-746, doi:10.1152/ajpgi.00056.2016.

165. Mussbacher, M.; Brunnthaler, L.; Panhuber, A.; Starlinger, P.; Assinger, A. Till Death Do Us Part-The Multifaceted Role of Platelets in Liver Diseases. Int J Mol Sci 2021, 22, doi:10.3390/ijms22063113.

166. Chauhan, A.; Adams, D.H.; Watson, S.P.; Lalor, P.F. Platelets: No longer bystanders in liver disease. Hepatology 2016, 64, 1774-1784, doi:10.1002/hep.28526.

167. Grozovsky, R.; Giannini, S.; Falet, H.; Hoffmeister, K.M. Novel mechanisms of platelet clearance and thrombopoietin regulation. Curr Opin Hematol 2015, 22, 445-451, doi:10.1097/MOH.0000000000000170.

168. Roberts, L.N.; Bernal, W. Incidence of Bleeding and Thrombosis in Patients with Liver Disease. Semin Thromb Hemost 2020, 46, 656-664, doi:10.1055/s-0040-1714205.

169. Malehmir, M.; Pfister, D.; Gallage, S.; Szydlowska, M.; Inverso, D.; Kotsiliti, E.; Leone, V.; Peiseler, M.; Surewaard, B.G.J.; Rath, D., et al. Platelet GPIbalpha is a mediator and potential interventional target for NASH and subsequent liver cancer. Nat Med 2019, 25, 641-655, doi:10.1038/s41591-019-0379-5.

170. Lisman, T.; Porte, R.J. The role of platelets in liver inflammation and regeneration. Semin Thromb Hemost 2010, 36, 170-174, doi:10.1055/s-0030-1251501.

171. Shido, K.; Chavez, D.; Cao, Z.; Ko, J.; Rafii, S.; Ding, B.S. Platelets prime hematopoietic and vascular niche to drive angiocrine-mediated liver regeneration. Signal Transduct Target Ther 2017, 2, doi:10.1038/sigtrans.2016.44.

172. Muller, K.A.; Chatterjee, M.; Rath, D.; Geisler, T. Platelets, inflammation and anti-inflammatory effects of antiplatelet drugs in ACS and CAD. Thromb Haemost 2015, 114, 498-518, doi:10.1160/TH14-11-0947.

173. Capodanno, D.; Bhatt, D.L.; Eikelboom, J.W.; Fox, K.A.A.; Geisler, T.; Michael Gibson, C.; Gonzalez-Juanatey, J.R.; James, S.; Lopes, R.D.; Mehran, R., et al. Dual-pathway inhibition for secondary and tertiary antithrombotic prevention in cardiovascular disease. Nat Rev Cardiol 2020, 17, 242-257, doi:10.1038/s41569-019-0314-y.

174. Sibbing, D.; Aradi, D.; Jacobshagen, C.; Gross, L.; Trenk, D.; Geisler, T.; Orban, M.; Gori, T.; Hadamitzky, M.; Merkely, B., et al. A randomised trial on platelet function-guided de-escalation of antiplatelet treatment in ACS patients undergoing PCI. Rationale and design of the Testing Responsiveness to Platelet Inhibition on Chronic Antiplatelet Treatment for Acute Coronary Syndromes (TROPICAL-ACS) Trial. Thromb Haemost 2017, 117, 188-195, doi:10.1160/TH16-07-0557.

175. Rajagopal, S.; Kim, J.; Ahn, S.; Craig, S.; Lam, C.M.; Gerard, N.P.; Gerard, C.; Lefkowitz, R.J. Beta-arrestin- but not G proteinmediated signaling by the "decoy" receptor CXCR7. Proc Natl Acad Sci U S A 2010, 107, 628-632, doi:10.1073/pnas.0912852107.

176. Naumann, U.; Cameroni, E.; Pruenster, M.; Mahabaleshwar, H.; Raz, E.; Zerwes, H.G.; Rot, A.; Thelen, M. CXCR7 functions as a scavenger for CXCL12 and CXCL11. PLoS One 2010, 5, e9175, doi:10.1371/journal.pone.0009175.

177. Mahabaleshwar, H.; Tarbashevich, K.; Nowak, M.; Brand, M.; Raz, E. beta-arrestin control of late endosomal sorting facilitates decoy receptor function and chemokine gradient formation. Development 2012, 139, 2897-2902, doi:10.1242/dev.080408.

178. Tobia, C.; Chiodelli, P.; Barbieri, A.; Buraschi, S.; Ferrari, E.; Mitola, S.; Borsani, G.; Guerra, J.; Presta, M. Atypical Chemokine Receptor 3 Generates Guidance Cues for CXCL12-Mediated Endothelial Cell Migration. Front Immunol 2019, 10, 1092, doi:10.3389/fimmu.2019.01092.

179. Mahabaleshwar, H.; Boldajipour, B.; Raz, E. Killing the messenger: The role of CXCR7 in regulating primordial germ cell migration. Cell Adh Migr 2008, 2, 69-70, doi:10.4161/cam.2.2.6027.

180. Uto-Konomi, A.; McKibben, B.; Wirtz, J.; Sato, Y.; Takano, A.; Nanki, T.; Suzuki, S. CXCR7 agonists inhibit the function of CXCL12 by down-regulation of CXCR4. Biochem Biophys Res Commun 2013, 431, 772-776, doi:10.1016/j.bbrc.2013.01.032. 
181. Boehm, M.; Beaumont, K.; Jones, R.; Kalgutkar, A.S.; Zhang, L.; Atkinson, K.; Bai, G.; Brown, J.A.; Eng, H.; Goetz, G.H., et al. Discovery of Potent and Orally Bioavailable Macrocyclic Peptide-Peptoid Hybrid CXCR7 Modulators. J Med Chem 2017, 60, 9653-9663, doi:10.1021/acs.jmedchem.7b01028.

182. Adlere, I.; Caspar, B.; Arimont, M.; Dekkers, S.; Visser, K.; Stuijt, J.; de Graaf, C.; Stocks, M.; Kellam, B.; Briddon, S., et al. Modulators of CXCR4 and CXCR7/ACKR3 Function. Mol Pharmacol 2019, 96, 737-752, doi:10.1124/mol.119.117663.

183. Lounsbury, N. Advances in CXCR7 Modulators. Pharmaceuticals (Basel) 2020, 13, doi:10.3390/ph13020033.

184. Kumar, R.; Tripathi, V.; Ahmad, M.; Nath, N.; Mir, R.A.; Chauhan, S.S.; Luthra, K. CXCR7 mediated Gialpha independent activation of ERK and Akt promotes cell survival and chemotaxis in T cells. Cell Immunol 2012, 272, 230-241, doi:10.1016/j.cellimm.2011.09.015.

185. Humpert, M.L.; Pinto, D.; Jarrossay, D.; Thelen, M. CXCR7 influences the migration of B cells during maturation. Eur J Immunol 2014, 44, 694-705, doi:10.1002/eji.201343907.

186. Banisadr, G.; Podojil, J.R.; Miller, S.D.; Miller, R.J. Pattern of CXCR7 Gene Expression in Mouse Brain Under Normal and Inflammatory Conditions. J Neuroimmune Pharmacol 2016, 11, 26-35, doi:10.1007/s11481-015-9616-y.

187. Schonemeier, B.; Kolodziej, A.; Schulz, S.; Jacobs, S.; Hoellt, V.; Stumm, R. Regional and cellular localization of the CXC112/SDF-1 chemokine receptor CXCR7 in the developing and adult rat brain. J Comp Neurol 2008, 510, 207-220, doi:10.1002/cne.21780.

188. Montpas, N.; St-Onge, G.; Nama, N.; Rhainds, D.; Benredjem, B.; Girard, M.; Hickson, G.; Pons, V.; Heveker, N. Ligandspecific conformational transitions and intracellular transport are required for atypical chemokine receptor 3-mediated chemokine scavenging. J Biol Chem 2018, 293, 893-905, doi:10.1074/jbc.M117.814947.

189. Freitas, C.; Desnoyer, A.; Meuris, F.; Bachelerie, F.; Balabanian, K.; Machelon, V. The relevance of the chemokine receptor ACKR3/CXCR7 on CXCL12-mediated effects in cancers with a focus on virus-related cancers. Cytokine Growth Factor Rev 2014, 25, 307-316, doi:10.1016/j.cytogfr.2014.04.006.

190. Santagata, S.; Ierano, C.; Trotta, A.M.; Capiluongo, A.; Auletta, F.; Guardascione, G.; Scala, S. CXCR4 and CXCR7 Signaling Pathways: A Focus on the Cross-Talk Between Cancer Cells and Tumor Microenvironment. Front Oncol 2021, 11, 591386, doi:10.3389/fonc.2021.591386.

191. Shi, Y.; Riese, D.J., 2nd; Shen, J. The Role of the CXCL12/CXCR4/CXCR7 Chemokine Axis in Cancer. Front Pharmacol 2020, 11, 574667, doi:10.3389/fphar.2020.574667.

192. Puchert, M.; Engele, J. The peculiarities of the SDF-1/CXCL12 system: in some cells, CXCR4 and CXCR7 sing solos, in others, they sing duets. Cell Tissue Res 2014, 355, 239-253, doi:10.1007/s00441-013-1747-y.

193. Berahovich, R.D.; Zabel, B.A.; Penfold, M.E.; Lewen, S.; Wang, Y.; Miao, Z.; Gan, L.; Pereda, J.; Dias, J.; Slukvin, II, et al. CXCR7 protein is not expressed on human or mouse leukocytes. J Immunol 2010, 185, 5130-5139, doi:10.4049/jimmunol.1001660.

194. Sanchez-Martin, L.; Sanchez-Mateos, P.; Cabanas, C. CXCR7 impact on CXCL12 biology and disease. Trends Mol Med 2013, 19, 12-22, doi:10.1016/j.molmed.2012.10.004.

195. Odemis, V.; Lipfert, J.; Kraft, R.; Hajek, P.; Abraham, G.; Hattermann, K.; Mentlein, R.; Engele, J. The presumed atypical chemokine receptor CXCR7 signals through G(i/o) proteins in primary rodent astrocytes and human glioma cells. Glia 2012, 60, 372-381, doi:10.1002/glia.22271.

196. Nguyen, H.T.; Reyes-Alcaraz, A.; Yong, H.J.; Nguyen, L.P.; Park, H.K.; Inoue, A.; Lee, C.S.; Seong, J.Y.; Hwang, J.I. CXCR7: a beta-arrestin-biased receptor that potentiates cell migration and recruits beta-arrestin2 exclusively through Gbetagamma subunits and GRK2. Cell Biosci 2020, 10, 134, doi:10.1186/s13578-020-00497-x. 
197. Balabanian, K.; Lagane, B.; Infantino, S.; Chow, K.Y.; Harriague, J.; Moepps, B.; Arenzana-Seisdedos, F.; Thelen, M.; Bachelerie, F. The chemokine SDF-1/CXCL12 binds to and signals through the orphan receptor RDC1 in T lymphocytes. J Biol Chem 2005, 280, 35760-35766, doi:10.1074/jbc.M508234200. 